\title{
Análise regional da competitividade da indústria mineira utilizando os microdados da PIA, 1996-2006
}

\author{
Antonio Braz de Oliveira e Silva \\ Doutor em Ciência da Informação e \\ Analista do IBGE-MG \\ Juliana Dias Alves \\ Mestre em Economia e \\ Analista do IBGE-MG
}

\section{Palauras-chave \\ desempenho industrial, competitividade, indústria regional mineira.}

\section{Classificação JEL R12.}

\section{Key words}

industrial performance,

competitiveness, regional industry.

JEL Classification R12.

\section{Resumo}

O objetivo do artigo é analisar o comportamento da indústria extrativa e de transformação nas regiões de Minas Gerais, utilizando os indicadores de emprego, remunerações, produto industrial e produtividade, complementado por um indicador de competitividade relativa. Este índice é obtido mediante a relação entre as séries de salário real e de produtividade do trabalho da região estudada frente a uma região de referência. Inicialmente, compara-se o comportamento da indústria no estado em relação ao Brasil, para se determinar o seu comportamento relativo. Em seguida, a mesma análise é feita para as regiões mineiras, tomando-se o total do estado como referência. Para a análise utilizou-se a base de dados da Pesquisa Industrial Anual para o período 1996 e 2006. Para as regiões do estado foram usadas as informações do estrato certo da pesquisa, o que permitiu o cruzamento das informações de emprego e de geração de renda.

\section{Abstract}

This article analyses manufacturing and mining industry performance in Minas Gerais state regions. Performance is measured using selected variables including employment numbers, remuneration, industrial product and productivity, complemented by an indicator of relative competitiveness. This indicator is the relation betweenthe series of real wages and labor productivity in a given region compared to a reference area. Brazil and Minas Gerais industrial performances are contrasted to identify the State's economic position. Then the same analysis is conducted for all regions of the State compared to the State as a whole. The information comes from the Annual Survey of Industry microdata files managed by the Brazilian Statistics Institute, IBGE, 1996 to 2006. 


\section{1_Introdução}

Durante a década de 1990, especialmente após 1994, com a redução das taxas de inflação e a consolidação da abertura comercial, observou-se uma mudança na estrutura industrial brasileira herdada do modelo de substituição de importações. Carvalho Jr. e Ruiz (2008) destacam que as principais alterações apontadas na maioria dos estudos sobre a indústria brasileira, após a abertura, são a redução nas taxas de lucro, o aumento na concentração industrial via fusões e aquisições, o aumento da participação do capital estrangeiro e da produtividade. Esta última está associada à modernização das firmas e ao aumento da concorrência de bens importados.

Assim, por exemplo, Feijó, Carvalho e Rodrigues (2003) concluem que houve uma concentração na indústria brasileira, movimento correlacionado com o aumento de produtividade observado na década de 1990 e com o aumento da participação relativa da mão de obra com maior número de anos de estudo no emprego industrial. Os autores constataram ainda aumento da participação do capital estrangeiro no controle das empresas e uma forte correlação entre esse controle e níveis mais elevados de produtividade.
Moreira (1999) destacou que, ao longo dos anos 1990, houve aumento significativo do coeficiente de importação da indústria de transformação brasileira, em todas as atividades, ainda que de forma diferenciada, sendo mais pronunciado nos setores mais intensivos em tecnologia. Em termos da importância do mercado externo, o coeficiente de exportações (exportação/produção), para a média da indústria de transformação, passou de 8,8\% para 14,8\%, entre 1989 e 1998 (Moreira, 1999).

Essa alteração estrutural na oferta de bens indica que houve mudanças na estrutura produtiva, com alguns setores se modernizando e outros diminuindo sua importância no decorrer do processo de ajuste às novas condições de mercado. Observa-se também expressivo aumento na produtividade do trabalho para aqueles que se modernizaram, mas com "marcantes diferenças entre os setores" (Bonelli, 2002, p. 9-10). Parte do aumento da produtividade pode ser buscada no desaparecimento das empresas mais ineficientes, uma vez que, até então, estavam garantidas por um regime comercial de alta proteção (Bonelli, 2002).

As reformas resultantes da implementação do Plano Real tiveram significativo impacto na estrutura industrial, e 
Primeiro ano da nova série da Pesquisa Industrial Mensal - Produção Física (PIM-PF), do IBGE. a parcela da indústria que resistiu às mudanças se modernizou e aumentou a sua competitividade. Deve-se assinalar que, nos primeiros anos do plano de estabilização, o câmbio supervalorizado incentivava as importações e prejudicava as exportações. O que se pode dizer é que as mudanças tiveram efeitos diferenciados, tanto do ponto de vista setorial quanto regional. Observa-se que a modernização decorreu de investimentos em novos equipamentos, isto é, conhecimentos embutidos nos bens de capital, e não pela adoção de inovações criadas pelas próprias empresas (Moreira, 1999). Já Bonelli (2002) destaca que, na década de 1990 , se rompeu a trajetória de taxas decrescentes de aumento da produtividade que havia chegado, até mesmo, a ser negativo na década de 1980. Para a segunda metade dos anos 90, esse autor estimou um crescimento de produtividade na indústria de transformação de 8,3\% ao ano.

Dessa forma, fatores macroeconômicos, como a mudança no regime industrial e o plano de estabilização econômica, conjugaram-se com aspectos microeconômicos, como o aumento da concorrência internacional com produtos de outros países, obrigando as empresas brasileiras a investir, modernizar-se e se especializar, gerando, assim, produtos com maior qualidade e preços mais competitivos (Netto e Curado, 2005). Como consequência, ao longo dos anos 1990, foram observados estes efeitos sobre a indústria de transformação: sua redução, em termos relativos, com a queda de sua participação no PIB, de 26,6\% em 1990 para 17,2\% em 2000 (Ipeadata, 2008) e no emprego, de $15,5 \%$ para $12,4 \%$ do emprego total, entre 1990 e 2000 (Bonelli, 2002).

Esses movimentos tiveram desdobramentos distintos nos Estados brasileiros. Valendo-se dos indicadores de produção física da Pesquisa Industrial Mensal do IBGE (Sidra, 2008) e tomando-se por base o ano de 1991, ${ }^{1}$ observa-se que, em Minas Gerais, a indústria de transformação, até 2006, apresentava um crescimento de 54\% (2,9\% a.a.) contra 39,8\% do País (2,3\% a.a.). Na indústria extrativa mineral, embora o desempenho estadual tenha sido satisfatório (3,9\% a.a.), o desempenho nacional, puxado pelo crescimento da produção de petróleo no Estado do Rio de Janeiro, foi bastante superior (7,0\% a.a.). Fazendo-se a mesma comparação para o período após o Plano de Estabilização, isto é, a base sendo a média de 1994, o crescimento da indústria de transformação 
em Minas Gerais, até 2006, situou-se em 2,8\% ao ano contra 1,9\% do Brasil como um todo. Esse desempenho reforça a tese de aumento da participação da indústria de transformação estadual no total do País (Minas Gerais, 2002).

Em termos da estrutura industrial mineira, segundo dados da Pesquisa Industrial Anual do IBGE (PIA-Empresa, IBGE, 1998 e 2008), em 1996 a atividade de "Produção de ferro-gusa e de ferroligas" representava $11,4 \%$ do $\mathrm{Va}$ lor da Transformação Industrial (VIT) da indústria geral, caindo para 3,0\% em 2006. Por outro lado, a atividade de "Extração de minério de ferro" aumentou, no mesmo período, sua participação de $7,8 \%$ para $13,3 \%$, e a atividade de "Siderurgia", de 3,7\% para 16\%. Em conjunto, as atividades de "Fabricação de automóveis, caminhonetas e utilitários" e "Fabricação de peças e acessórios para veículos automotores" perderam participação de $12,0 \%$ para $11,1 \%$ no total do VTI, mas a segunda tornou-se mais expressiva nesse conjunto (de 23,6\% em 1996 para 33,1\% em 2006), indicando mudanças na organização da indústria automobilística estadual. Todos esses movimentos afetam a distribuição espacial da produção industrial no Estado e requerem uma análise mais aprofundada de suas consequências.

\section{2_Justificativa}

Pesquisas e estudos recentes sobre economia regional são limitados pela disponibilidade de informações para níveis geográficos inferiores aos das Unidades da Federação. Assim, para análise das meso e microrregiões, utiliza-se basicamente informação sobre o emprego formal, eventualmente complementada por informações parciais sobre a atividade ou a região. Análises mais completas, empregando amplo conjunto de variáveis, não são feitas por regiões.

Por exemplo, Gonçalves et al. (2003) analisam a competitividade de Minas Gerais vis-à-vis o Brasil, para o período 1985-2000, tendo como referência a Pesquisa Industrial Mensal do IBGE, tanto para produção física quanto para salários e horas pagas na produção. Os autores utilizam como indicador o Índice de Custo Relativo (ICUR), que mostra a competitividade potencial relativa para cada setor industrial do Estado em relação ao Brasil. ${ }^{2}$

Utilizando, basicamente, o mesmo indicador (ICUR), Toyoshima e Silva (2000) analisaram a competitivida-
Esse mesmo índice foi utilizado no presente artigo, e sua definição encontra-se mais adiante. 
de da indústria mineira para o período 1985-1996, empregando a mesma fonte de informações do trabalho anteriormente citado.

Figueiredo e Diniz (2000) estudam a distribuição regional, por microrregião, ${ }^{3}$ da indústria mineira para o período compreendido entre 1970 e 1994. Foram utilizadas 61 microrregiões, e a base de dados foi construída com informações de diversas fontes. Segundo os autores, o pessoal ocupado e o Valor da Transformação Industrial (VTI) entre 1970 e 1985 foram obtidos dos Censos Industriais do IBGE (1970, 1975, 1980 e 1985). Os censos foram interrompidos após 1985, e os autores recorreram às informações de pessoal ocupado fornecida pela Relação Anual das Informações Sociais (RAIS, do Ministério do Trabalho e Emprego) para 1990 e 1994. Para substituir o VTI, eles usaram a informação do PIB industrial, calculado pela Fundação João Pinheiro. As microrregiões foram reunidas em cinco grupos, de acordo com o dinamismo apresentado, medido pela variação no emprego. Os dados referentes ao produto industrial foram usados para analisar a evolução da participação de cada microrregião no total do Estado, e, assim, não foram gerados indicadores sobre a produtividade da mão de obra.
A questão regional aparece ainda na forma de Arranjos Produtivos Locais (APL) no estudo realizado pelo Banco de Desenvolvimento Econômico de Minas Gerais (Minas Gerais, 2002). Na delimitação dos APLs, foram utilizadas informações do emprego formal provenientes da RAIS. Outros trabalhos semelhantes (ver, por exemplo, Crocco et al., 2001), que analisam as regiões definidas como as áreas de influência dos APLs, partem do mesmo tipo de informação, complementadas ou não por outros dados obtidos ad hoc. De qualquer forma, as informações que permitem a generalização de metodologias de identificação e análise da evolução dos APLs utilizam como fonte a RAIS (por exemplo, Britto e Albuquerque, 2001).

O presente estudo estende a análise sobre a competitividade, medida pelo ICUR, da indústria mineira para o período de 1996 a 2006 e amplia a análise para as regiões de Minas Gerais, com base nas unidades locais (ULs) do estrato certo da Pesquisa Industrial Anual. Como se verá na seção seguinte, essas ULs são levantadas de forma censitária. Com sua utilização, torna-se possível combinar variáveis de emprego, custo de mão de obra, PIB industrial e da produtividade do trabalho na análise regional. 


\section{3_Fonte de dados: a Pesquisa Industrial Anual}

Nesse trabalho, a fonte de dados utilizada foi a Pesquisa Industrial Anual - Empresa (PIA-Empresa) (IBGE, 2008), realizada pelo IBGE. A partir de 1996, essa pesquisa passou a ser apresentada no formato atual, sendo aquele ano, portanto, o melhor para se iniciarem séries anuais de análise. A PIA tem como referencial de corte todas as firmas industriais (seções C e D da CNAE) (IBGE, $2004)^{4}$ com mais de cinco pessoas ocupadas em 31 de dezembro do ano pesquisado, e a unidade de investigação é a empresa cuja principal receita provém da atividade industrial. Empresas com múltiplas localizações e/ou múltiplas atividades econômicas têm suas informações compiladas com a agregação das informações originárias das unidades locais (ULs). A seleção das empresas da PIA é feita por amostragem estratificada por corte em dois níveis. No primeiro nível, encontram-se os estratos naturais, especificados a partir do cruzamento da Unidade da Federação (UF) da sede da empresa com a sua classificação na CNAE. No segundo nível, os estratos finais são definidos de acordo com o número total de pessoas ocupadas. $\mathrm{O}$ estrato final cer- to é formado pelas empresas que ocupam 30 ou mais pessoas, e o estrato final amostrado, pelas empresas que ocupam entre 5 e 29 pessoas. Para as empresas do estrato certo, aplica-se o questionário completo que investiga cerca de 150 variáveis e possui informações adicionais em relação ao estrato amostrado, como, por exemplo, se a firma atua em diversas localizações geográficas. Colhem-se também dados sobre as unidades locais (ULs), tais como: pessoal ocupado, salários, receita líquida de vendas, consumo de matérias-primas, custos diretos de produção e outros custos e despesas. $\mathrm{O}$ questionário simplificado, com cerca de 60 variáveis, é aplicado às empresas do estrato amostrado.

Considerando-se as características da PIA, pode-se pensar nas análises a ser realizadas, tanto para o total do Estado de Minas Gerais quanto para as suas regiões, dado que o estrato certo permite boa representatividade diante do universo da pesquisa para a maior parte das variáveis econômicas relevantes (Tabela 1).

Tendo em vista as exigências da legislação ${ }^{5}$ e o objetivo de fazer uma análise regional mais desagregada da indústria mineira, desenvolveu-se uma classificação das atividades, com oito grupamentos, de forma a se permitir a comparação
A última revisão da CNAE resultou na versão 2.0 adotada na Pesquisa Industrial Anual a partir do ano de referência de 2007. Somente em 2009, porém, foram divulgados os resultados nesta nova versão. Para o ano de referência de 2007, a PIA-Empresa foi divulgada nas duas versões (CNAE 1.0 e 2.0).

5 A divulgação dos resultados não pode ferir a legislação que trata do sigilo estatístico, $\mathrm{e}$, dessa forma, qualquer cruzamento de região do Estado com a atividade econômica deve contar com no mínimo três informantes. Como a intenção é fazer uma análise temporal da indústria, essa condição deve ser satisfeita ao longo de todo o período, sob pena de não se divulgar resultados inteiramente comparáveis. 
Tabela 1_Cobertura do Estrato Certo para as principais variáveis selecionadas, 1996 e 2006 - Minas Gerais

\begin{tabular}{|c|c|c|c|c|c|c|c|c|c|c|c|c|c|c|}
\hline \multirow[t]{2}{*}{ Atividades/Variáveis/Ano } & \multicolumn{2}{|c|}{$\begin{array}{l}\text { Unidades } \\
\text { Locais } \\
\text { (ULs) }\end{array}$} & \multicolumn{2}{|c|}{$\begin{array}{c}\text { Pessoal } \\
\text { Ocupado } \\
\text { (PO) }\end{array}$} & \multicolumn{2}{|c|}{$\begin{array}{c}\text { Salários } \\
\text { e outras } \\
\text { remunera- } \\
\text { ções }\end{array}$} & \multicolumn{2}{|c|}{$\begin{array}{c}\text { Encargos } \\
\text { sociais }\end{array}$} & \multicolumn{2}{|c|}{$\begin{array}{l}\text { Custo das } \\
\text { Operações } \\
\text { Industrais } \\
\text { (COI) }\end{array}$} & \multicolumn{2}{|c|}{$\begin{array}{l}\text { Valor } \\
\text { Bruto da } \\
\text { Produção } \\
\text { (VBP) }\end{array}$} & \multicolumn{2}{|c|}{$\begin{array}{l}\text { Valor da } \\
\text { transfor- } \\
\text { mação } \\
\text { industrial }\end{array}$} \\
\hline & 1996 & 2006 & 1996 & 2006 & 1996 & 2006 & 1996 & 2006 & 1996 & 2006 & 1996 & 2006 & 1996 & 2006 \\
\hline Alimentos, bebidas e fumo & 23,4 & 17,0 & 61,8 & 68,5 & 85,1 & 86,7 & 89,1 & 88,9 & 93,2 & 95,1 & 94,8 & 95,8 & 96,8 & 96,9 \\
\hline Extrativa & 45,2 & 40,4 & 72,5 & 73,4 & 76,9 & 76,5 & 96,1 & 85,9 & 94,4 & 97,4 & 94,5 & 97,1 & 94,6 & 97,0 \\
\hline Madeira, celulose, edição e móveis $(*)$ & 13,7 & 15,3 & 61,2 & 58,4 & 90,3 & 92,3 & 86,2 & 86,2 & 85,2 & 88,2 & 85,3 & 86,0 & 85,4 & 83,5 \\
\hline Máquinas, equipamentos e veículos & 32,8 & 33,2 & 88,1 & 87,4 & 93,8 & 95,1 & 97,3 & 95,5 & 98,1 & 97,3 & 97,6 & 96,9 & 96,8 & 96,2 \\
\hline Metálicos & 24,1 & 22,2 & 81,6 & 77,1 & 91,9 & 90,0 & 96,3 & 89,0 & 95,5 & 97,3 & 95,9 & 97,0 & 96,3 & 96,5 \\
\hline Não metálicos & 25,1 & 20,2 & 71,1 & 62,0 & 90,8 & 91,1 & 92,9 & 89,5 & 91,8 & 92,6 & 92,1 & 92,6 & 92,2 & 92,5 \\
\hline Petróleo, álcool, farmacêutica e química & 34,6 & 36,5 & 77,3 & 79,8 & 82,7 & 88,1 & 93,6 & 90,6 & 96,3 & 96,9 & 95,8 & 96,7 & 94,7 & 96,5 \\
\hline Têxtil, vestuário, couro e calçados & 16,6 & 18,7 & 65,5 & 64,4 & 91,5 & 94,6 & 83,0 & 82,2 & 81,2 & 82,0 & 82,8 & 81,6 & 84,6 & 81,1 \\
\hline INDÚSTRIA GERAL & 22,8 & 21,7 & 72,3 & 72,0 & 88,2 & 90,1 & 93,6 & 90,0 & 94,2 & 95,8 & 94,4 & 95,5 & 94,6 & 95,2 \\
\hline
\end{tabular}

(*) Inclui "Reciclagem".

Fonte: Microdados da PIA/IBGE. Elaboração dos autores.

Para a correspondência da classificação com a CNAE, ver o Anexo.

Deve-se esclarecer que as informações básicas são obtidas do questionário aplicado às empresas. As variáveis utilizadas para as unidades locais (ULs), unidade de análise usada neste estudo são variáveis derivadas, com exceção do pessoal ocupado total e dos salários, retiradas e outras remunerações (IBGE, 2008). regional e temporal, com um mínimo de detalhamento das atividades produtivas e uma classificação com oito regiões, que correspondem à agregação das dez regiões de planejamento do Estado. Essa agregação permite que se analise a série com as oito atividades mencionadas.

$\mathrm{Na}$ Tabela 1, estão apresentadas as oito atividades, ${ }^{6}$ assim como a cobertura do estrato certo em cada uma delas. $\mathrm{Na}$ Figura 1, encontra-se o mapa com as dez regiões de planejamento de Minas Gerais e as oito regiões mencionadas.

\section{4_Principais variáveis utilizadas}

As principais variáveis usadas neste estudo foram obtidas diretamente da base de dados da PIA ${ }^{7}$. São elas:

i. Pessoal Ocupado (PO), pessoas assalariadas com vínculo empregatício ou sem ele;

ii. Salários, Retiradas e Outras Remunerações, que são as importâncias pagas no ano, a título de salários fixos, pró-labore e outras retiradas, registradas em bruto; 
Figura 1_Regiões de Planejamento e Regiões agregadas

10 Regiões de Planejamento

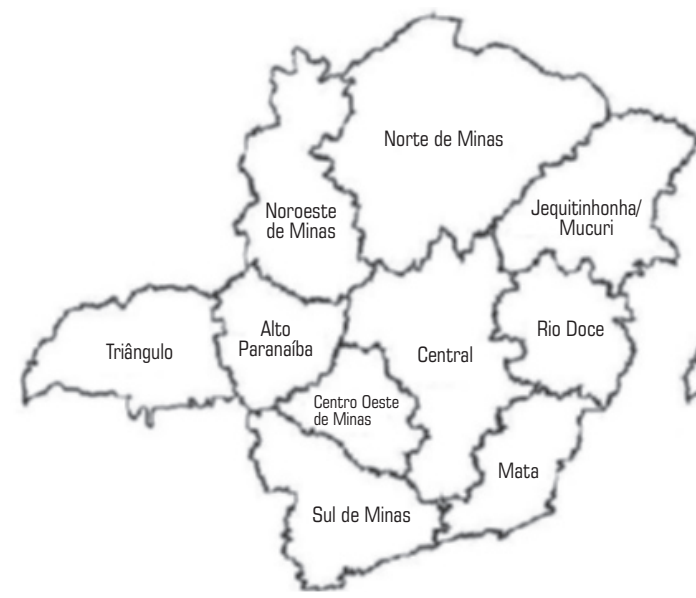

iii. Encargos Sociais e Trabalhistas, que correspondem aos valores referentes à parte do empregador das contribuições para as previdências social e privada, o FGTS e os outros benefícios concedidos aos empregados;

iv. Valor Bruto da Produção Industrial (VBP), definido como a soma de vendas de produtos e serviços industriais, a variação dos estoques dos produtos acabados e em elaboração, e a produ-
Agregação com 8 regiões

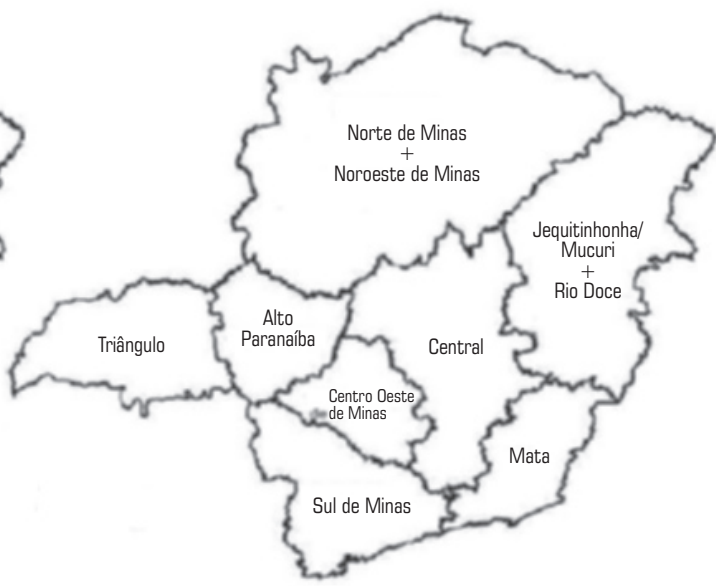

ção própria realizada para o ativo imobilizado;

v. O Valor da Transformação Industrial (VTI), calculado como a diferença entre o valor bruto da produção industrial e os custos das operações industriais.

Foram ainda definidas algumas variáveis derivadas, para efeito da apresentação da primeira leitura dos dados. São elas: a produtividade da mão de obra, em termos nominais, definida como a razão entre o Valor da Transformação Indus- 
trial e o Pessoal (VTI/PO) e o tamanho médio da unidade local, com três variações: o Valor da Transformação Industrial nominal por Unidade Local (VTI/ UL), o Pessoal Ocupado por Unidade Local (PO/UL) e o Valor Bruto da Produção Industrial nominal por Unidade Local (VBP/UL).

\section{5_Visão geral dos dados: um panorama da indústria no Brasil e em Minas Gerais}

\section{1_ Indicadores básicos}

No Brasil, o grupamento "Alimentos, bebidas e fumo" se tornou, em 2006, o principal gerador de emprego, respondendo por cerca de $20,5 \%$ do total contra $18,3 \%$ em 1996, quando se encontrava na $3^{\text {a }}$ posição, conforme a Tabela 2 , a seguir. Observa-se ainda que os setores mais tradicionais, representados por esse grupo e pelas atividades englobadas em "Têxtil, vestuário, couro e calçados" ( $3^{a}$ posição na geração de emprego em 2006), respondem, em conjunto, por 38,9\% do emprego industrial. Destaca-se ainda a atividade de produção de "Máquinas, equipamentos e veículos", que passou de $18,6 \%$ para 19,2\% do emprego total.

Em Minas Gerais, os mesmos setores se destacam. Em 1996, em con- junto, eles respondiam por 52,6\% do emprego industrial, percentual que se elevou para 55,7\% em 2006. Destaca-se que a indústria de produtos metálicos, na qual se encontra a indústria siderúrgica, teve sua participação no emprego reduzida de $16,7 \%$ para $14,1 \%$ no mesmo período.

A distribuição da massa salarial paga aos empregados mostra diferenças importantes em relação ao emprego. No Brasil, as duas atividades que apresentavam o maior valor para o total dos salários pagos, tanto em 1996 quanto em 2006 - "Máquinas, equipamentos e veículos" e "Petróleo, álcool, farmacêutica e química" -, representavam, conjuntamente, $45,7 \%$ e 46,6\%, respectivamente, da massa salarial.

Em Minas Gerais, são as atividades de "Máquinas, equipamentos e veículos" e fabricação de produtos "Metálicos" que respondem, em conjunto, por 44,7\% e 47,8\%, em 1996 e 2006, da massa salarial no Estado. Destaca-se ainda a queda de importância relativa da massa salarial e do emprego na atividade "Extrativa". No emprego, a queda de participação foi de $6,3 \%$ para $5,2 \%$ do total estadual no período analisado, enquanto a participação nos salários pagos reduziuse de $12,5 \%$ para $7,4 \%$. 
Tabela 2_Participação percentual das principais variáveis selecionadas, 1996 e 2006 - Brasil e Minas Gerais

\begin{tabular}{|c|c|c|c|c|c|c|c|c|}
\hline \multirow{2}{*}{ Atividades/Variáveis/Ano } & \multicolumn{2}{|c|}{ UL } & \multicolumn{2}{|c|}{ PO } & \multicolumn{2}{|c|}{ Massa Salarial } & \multicolumn{2}{|c|}{ VTI } \\
\hline & 1996 & 2006 & 1996 & 2006 & 1996 & 2006 & 1996 & 2006 \\
\hline \multicolumn{9}{|l|}{ Brasil } \\
\hline Alimentos, bebidas e fumo & 17,7 & 16,1 & 18,3 & 20,5 & 14,3 & 14,6 & 18,6 & 16,6 \\
\hline Extrativa & 2,6 & 2,4 & 2,3 & 2,3 & 4,0 & 5,0 & 3,4 & 8,4 \\
\hline Madeira, celulose, edição e móveis $(*)$ & 21,0 & 20,3 & 15,1 & 13,7 & 12,1 & 10,7 & 12,1 & 9,2 \\
\hline Máquinas, equipamentos e veículos & 12,0 & 11,9 & 18,6 & 19,2 & 27,0 & 28,5 & 23,2 & 20,8 \\
\hline Metálicos & 9,7 & 11,0 & 9,1 & 9,1 & 10,4 & 10,4 & 9,3 & 11,2 \\
\hline Não metálicos & 7,5 & 8,0 & 5,0 & 5,1 & 3,7 & 3,8 & 3,4 & 3,2 \\
\hline Petróleo, álcool, farmacêutica e química & 9,2 & 9,1 & 13,1 & 11,8 & 18,8 & 18,0 & 22,2 & 25,6 \\
\hline Têxtil, vestuário, couro e calçados & 20,3 & 21,2 & 18,6 & 18,4 & 9,7 & 8,8 & 7,8 & 5,1 \\
\hline \multicolumn{9}{|l|}{ Minas Gerais } \\
\hline Alimentos, bebidas e fumo & 23,6 & 19,2 & 18,8 & 19,5 & 13,3 & 14,2 & 22,4 & 15,0 \\
\hline Extrativa & 4,8 & 4,7 & 6,3 & 5,2 & 12,5 & 7,4 & 9,8 & 14,9 \\
\hline Madeira, celulose, edição e móveis $(*)$ & 16,6 & 15,3 & 10,0 & 9,9 & 7,2 & 6,6 & 6,1 & 4,5 \\
\hline Máquinas, equipamentos e veículos & 7,1 & 7,7 & 15,5 & 16,9 & 18,6 & 23,8 & 18,2 & 18,5 \\
\hline Metálicos & 9,9 & 11,2 & 16,7 & 14,1 & 26,1 & 24,0 & 22,8 & 26,3 \\
\hline Não metálicos & 8,2 & 8,7 & 6,1 & 6,2 & 5,1 & 5,8 & 5,2 & 4,0 \\
\hline Petróleo, álcool, farmacêutica e química & 6,5 & 7,1 & 8,3 & 9,0 & 9,0 & 9,7 & 9,4 & 13,1 \\
\hline 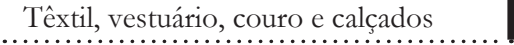 & 23,4 & 26,0 & 18,3 & 19,2 & 8,2 & 8,4 & 6,2 & 3,9 \\
\hline
\end{tabular}

As atividades que mais contribuem para a geração do V'TI, no Brasil, são: "Máquinas, equipamentos e veículos" (23,2\% em 1996 e 20,8\% em 2006), "Petróleo, álcool, farmacêutica e química" (22,2\% e $25,6 \%$, respectivamente) e "Alimentos, bebidas e fumo" $(18,6 \%$ e $16,6 \%)$. As mudanças observadas no pe- ríodo referem-se tanto a diferentes taxas de crescimento real quanto a mudanças nos preços relativos dos bens e serviços produzidos.

Em Minas Gerais, as principais atividades em 1996, em ordem de participação no VTI, eram fabricação de produtos "Metálicos" (22,8\%), seguida por 
"Alimentos, bebidas e fumo" (22,4\%) e "Máquinas, equipamentos e veículos" (18,2\%). Para 2006, mantém-se como mais importante a fabricação de produtos "Metálicos", que cresce sua participação para $26,3 \%$, mas há uma troca na ordem entre "Alimentos, bebidas e fumo”, cuja participação cai para 15,0\%, e a atividade "Máquinas, equipamentos e veículos", que aumenta a sua participação para 18,5\%. Destacam-se, também no período, as atividades da "Extrativa", cuja participação aumentou de 9,8\% para $14,9 \%$ do VTI. Nessa atividade, há sinais de mudanças estruturais significativas no seu funcionamento, uma vez que a ampliação do VTI veio acompanhada de queda expressiva na participação no emprego e na massa salarial.

Analisando-se apenas o estrato certo da PIA para Minas Gerais, percebe-se que a variação no período considerado é, nas maiorias dos casos, semelhante ao observado para o conjunto do Estado. A Tabela 3, a seguir, mostra a comparação da evolução das variações, tomando-se como referência a mutabilidade do salário do total das atividades no Brasil. Nota-se que a evolução estimada para a massa salarial da atividade "Extrativa" em Minas Gerais, nos dois recortes de análise, ficou significativamen- te abaixo dos demais resultados, tanto para a massa salarial das demais atividades quanto da variação nominal das outras variáveis estudadas. Destaca-se ainda que, com exceção da atividade "Têxtil, vestuário, couro e calçados”, todas as demais apresentam evolução do VBP e VTI bem acima da evolução média da massa salarial. Trata-se de uma indicação de redução dos custos salariais em relação ao valor da produção e no que diz respeito à renda gerada, podendo ser considerado um indicador indireto do aumento da produtividade do trabalho que não foi repassado aos salários. Os dados mostram que, com exceção da atividade "Alimentos, bebidas e fumo" para Minas Gerais (total e estrato certo) e "Têxtil, vestuário, couro e calçados" para o estrato certo em Minas Gerais, isso ocorreu em todas as demais atividades. Para o total estadual e para o estrato certo, observou-se uma evolução do V'TI por trabalhador acima da evolução do salário médio.

Este estudo pode ainda ser complementado pela análise da evolução do tamanho médio das unidades locais, medida em termos de número médio de pessoas ocupadas (PO/UL). Com exceção da atividade de "Alimentos, bebidas e fumo", o tamanho médio das unidades 
Tahela 3_ Comparação da evolução nominal das variáveis selecionadas, 1996-2006 - Brasil, Minas Gerais Total e Estrato certo (variação do salário do total das atividades, Brasil $=100$ )

\begin{tabular}{|c|c|c|c|c|c|c|c|c|c|}
\hline \multirow[b]{2}{*}{ Atividades/Variáveis/Regiões } & \multicolumn{3}{|c|}{ Salários } & \multicolumn{3}{|c|}{ VBP } & \multicolumn{3}{|c|}{ VTI } \\
\hline & Brasil & MG & $\begin{array}{c}\text { Estrato } \\
\text { Certo }\end{array}$ & Brasil & MG & $\begin{array}{c}\text { Estrato } \\
\text { Certo }\end{array}$ & Brasil & MG & $\begin{array}{c}\text { Estrato } \\
\text { Certo }\end{array}$ \\
\hline INDÚSTRIA GERAL & 100,0 & 106,0 & 109,7 & 188,0 & 205,2 & 208,5 & 169,6 & 206,3 & 208,2 \\
\hline Alimentos, bebidas e fumo & 110,7 & 124,9 & 128,6 & 164,6 & 143,1 & 145,4 & 143,9 & 115,4 & 115,6 \\
\hline Extrativa & 130,0 & 30,2 & 29,7 & 444,8 & 351,8 & 363,4 & 515,4 & 348,2 & 358,7 \\
\hline Madeira, celulose, edição e móveis & 80,6 & 83,6 & 86,8 & 128,2 & 155,0 & 156,8 & 112,2 & 133,4 & 128,9 \\
\hline Máquinas, equipamentos e veículos & 106,2 & 169,9 & 173,2 & 195,0 & 199,8 & 197,6 & 145,2 & 210,1 & 208,4 \\
\hline Metálicos & 97,6 & 90,6 & 87,3 & 250,0 & 259,6 & 263,4 & 217,6 & 247,6 & 248,3 \\
\hline Não metálicos & 105,9 & 135,3 & 136,0 & 162,0 & 171,1 & 172,4 & 155,0 & 141,7 & 142,4 \\
\hline Petróleo, álcool, farmacêutica e química & 97,3 & 115,2 & 127,1 & 213,0 & 231,7 & 234,7 & 206,2 & 317,2 & 324,6 \\
\hline Têxtil, vestuário, couro e calçados & 86,1 & 103,7 & 109,6 & 95,1 & 100,1 & 97,6 & 86,6 & 104,0 & 96,9 \\
\hline
\end{tabular}

Fonte: Microdados da PIA/IBGE. Elaboração dos autores.

locais declinou no período analisado em todo o Estado. A combinação desses indicadores aponta na direção de mudanças importantes na organização das atividades, com a diminuição do número médio de pessoas ocupadas e a redução dos custos salariais em relação ao valor produzido. Uma análise mais completa, por regiões do Estado, será apresentada mais adiante. Na próxima seção, estão demonstrados indicadores de competitividade para as oito atividades descritas, comparando-se o Brasil (total e unidades produtivas de empresas com mais de 30 pessoas ocupadas) e Minas Gerais (total e ULs do estrato certo). Com isso, po- de-se ter uma ideia da evolução, no período considerado, da competitividade da indústria mineira perante o País.

\section{2_Competitividade: Minas Gerais versus Brasil}

Nesta seção, faz-se uma comparação da competitividade dos setores entre o Brasil, considerando o total e as ULs de empresas com mais de 30 pessoas ocupadas, e Minas Gerais, levando-se em conta o total e o estrato certo ajustado. Para Minas Gerais, o estrato certo foi ajustado em função das análises realizadas na base de dados das unidades locais: foram retiradas do painel aquelas ULs que 
8 Em outras palavras, a não eliminação dessas unidades pode gerar indicadores de difícil interpretação, como, por exemplo, produtividade negativa. Em muitos casos, a unidade local pode estar em implantação ou ter paralisado suas atividades durante uma parte do ano, e sua manutenção distorceria os resultados. Com isso, a representatividade do estrato certo se reduziu ligeiramente: considerando-se o VTI, houve redução, em relação aos valores originais, de cerca de $2 \%$ em 1996 e 1,3\% em 2006.

9 Idealmente, deveria se utilizar a produtividade total dos fatores. No entanto, devido aos problemas de estimativa desse indicador, no presente estudo, vai se trabalhar apenas com a produtividade da mão de obra. apresentaram VTI negativo no início e no final do período. Esse tipo de resultado, embora se dilua quando se analisa os dados agregados para o total do Estado, afeta a análise das regiões mineiras, sobretudo daquelas menos desenvolvidas. ${ }^{8}$ Para a análise da evolução da competitividade da indústria mineira, inicialmente se observa a evolução do custo médio da mão de obra no período, medido pela soma dos salários e pelas retiradas com os encargos sociais. A Tabela 4 , a seguir, mostra queda generalizada no custo unitário da mão de obra, com exceção da "indústria extrativa" no Brasil (para ambas as categorias, total e para as ULs de empresas com mais de 30 pessoas ocupadas) e da indústria de beneficiamento de minerais "Não metálicos" e da indústria de "Máquinas, equipamentos e veículos" em Minas Gerais (em ambas as categorias).

Outro componente relevante para a análise da competitividade é a produtividade. ${ }^{9}$ A Tabela 5 mostra a evolução da produtividade da mão de obra. Os resultados foram agregados nas oito atividades definidas previamente. Destaca-se a evolução positiva da indústria "Extrativa" e da indústria de "Máquinas, equipamentos e veículos" (em todas as quatro categorias analisadas); no Brasil, os resul- tados estão, em grande medida, relacionados com a indústria de extração de petróleo e gás natural. Em Minas Gerais, nas empresas com mais de 30 empregados, chama a atenção a evolução da indústria de produtos "Metálicos".

Os dois indicadores, tomados isoladamente, não permitem uma visão adequada da evolução relativa da competitividade do Estado. Dessa forma, define-se, para comparar o custo da mão de obra e a produtividade de uma região com uma área de referência, o índice de custo relativo - ICUR - de um setor 'i' definido como:

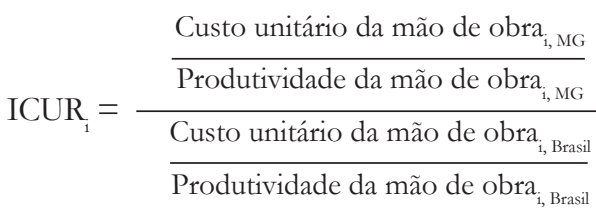

Sendo o custo unitário da mão de obra no setor ' $i$ ' definido como:

da mão de obra $_{i}=\frac{\text { Salários }_{i}+\text { Encargos Sociais }_{i}}{\text { População Ocupada }_{i}}$

e a produtividade da mão de obra no setor ' $i$ ' definida como:

${\underset{\text { Produtividade }}{\text { da } \text { ão de } \text { obra }_{\mathrm{i}}}}_{\text {População Ocupada }}$


Tabela 4_ Custo unitário da mão de obra, 1996 e 2006 - Brasil, empresas Brasil com mais de 30 P0, Minas Gerais, Estrato Certo de Minas Gerais ajustado - Valores a preços constantes inflacionados para 2006 pelo IPCA

\begin{tabular}{|c|c|c|c|c|c|c|c|c|}
\hline \multirow[b]{2}{*}{ Atividades/Ano/Regiões } & \multicolumn{4}{|c|}{1996} & \multicolumn{4}{|c|}{2006} \\
\hline & Brasil & $\begin{array}{c}\text { Brasil } \\
+\mathbf{3 0}\end{array}$ & $\begin{array}{l}\text { Minas } \\
\text { Gerais }\end{array}$ & $\begin{array}{c}\text { MG } \\
\text { Estrato } \\
\text { Certo } \\
\text { ajustado }\end{array}$ & Brasil & $\begin{array}{c}\text { Brasil } \\
+\mathbf{3 0}\end{array}$ & $\begin{array}{l}\text { Minas } \\
\text { Gerais }\end{array}$ & $\begin{array}{c}\text { MG } \\
\text { Estrato } \\
\text { Certo } \\
\text { ajustado }\end{array}$ \\
\hline Alimentos, bebidas e fumo & 21,7 & 24,5 & 16,0 & 19,9 & 17,8 & 19,5 & 14,6 & 17,5 \\
\hline Extrativa & 49,4 & 58,4 & 44,9 & 45,7 & 56,0 & 66,3 & 28,8 & 29,0 \\
\hline Madeira, celulose, edição e móveis & 22,4 & 27,3 & 16,5 & 22,6 & 19,7 & 24,4 & 13,5 & 18,1 \\
\hline Máquinas, equipamentos e veículos & 40,3 & 43,4 & 27,1 & 28,8 & 37,1 & 40,4 & 28,3 & 30,1 \\
\hline Metálicos & 31,9 & 37,0 & 35,5 & 39,9 & 28,7 & 34,5 & 34,1 & 39,6 \\
\hline Não metálicos & 20,6 & 25,7 & 18,8 & 23,0 & 18,9 & 24,1 & 18,9 & 26,0 \\
\hline Petróleo, álcool, farmacêutica e química & 39,9 & 43,1 & 24,5 & 25,2 & 38,2 & 42,3 & 21,8 & 23,3 \\
\hline Têxtil, vestuário, couro e calçados & 14,5 & 16,1 & 10,1 & 12,2 & 12,0 & 13,4 & 8,8 & 10,2 \\
\hline INDÚSTRIA GERAL & 27,8 & 31,8 & 22,7 & 26,9 & 25,0 & 28,9 & 20,1 & 24,4 \\
\hline
\end{tabular}

Fonte: Microdados da PIA/IBGE. Elaboração dos autores.

Tabela 5_ Produtividade da mão de obra, 1996 e 2006 - Brasil, empresas Brasil com mais de 30 PO,

Minas Gerais, Estrato Certo de Minas Gerais ajustado - Valores do VTI inflacionados para 2006 pela IPA/FGV

\begin{tabular}{|c|c|c|c|c|c|c|c|c|}
\hline \multirow[b]{2}{*}{ Atividades/Ano/Regiões } & \multicolumn{4}{|c|}{1996} & \multicolumn{4}{|c|}{2006} \\
\hline & Brasil & $\begin{array}{c}\text { Brasil } \\
+\mathbf{3 0}\end{array}$ & $\begin{array}{l}\text { Minas } \\
\text { Gerais }\end{array}$ & $\begin{array}{c}\text { MG } \\
\text { Estrato } \\
\text { Certo } \\
\text { ajustado }\end{array}$ & Brasil & $\begin{array}{c}\text { Brasil } \\
+\mathbf{3 0}\end{array}$ & $\begin{array}{l}\text { Minas } \\
\text { Gerais }\end{array}$ & $\begin{array}{c}\text { MG } \\
\text { Estrato } \\
\text { Certo } \\
\text { ajustado }\end{array}$ \\
\hline Alimentos, bebidas e fumo & 75,6 & 87,3 & 75,6 & 140,6 & 67,2 & 75,8 & 62,0 & 98,5 \\
\hline Extrativa & 165,2 & 192,1 & 155,1 & 248,2 & 308,9 & 373,3 & 232,3 & 358,8 \\
\hline Madeira, celulose, edição e móveis & 66,3 & 82,0 & 43,5 & 70,9 & 56,0 & 72,8 & 36,4 & 62,3 \\
\hline Máquinas, equipamentos e veículos & 86,9 & 93,9 & 77,7 & 93,0 & 90,3 & 98,7 & 88,1 & 103,9 \\
\hline Metálicos & 117,0 & 138,1 & 148,4 & 191,8 & 102,2 & 129,5 & 150,2 & 204,5 \\
\hline Não metálicos & 52,1 & 66,5 & 58,3 & 84,2 & 53,0 & 71,4 & 51,9 & 86,6 \\
\hline Petróleo, álcool, farmacêutica e química & 195,4 & 213,6 & 116,9 & 160,5 & 180,7 & 204,7 & 118,6 & 165,0 \\
\hline Têxtil, vestuário, couro e calçados & 23,1 & 26,9 & 17,2 & 29,2 & 23,2 & 26,6 & 16,3 & 25,8 \\
\hline INDÚSTRIA GERAL & 86,8 & 101,1 & 81,5 & 123,6 & 83,4 & 99,5 & 80,8 & 122,5 \\
\hline
\end{tabular}

Fonte: Microdados da PIA/IBGE. Elaboração dos autores. 
Dessa forma, o índice permite a comparação de uma região como uma área de referência, e sua vantagem competitiva pode ser decorrente de menores custos unitários da mão de obra, de maior produtividade dessa mesma mão de obra ou de combinações favoráveis desses dois fatores. Um ICUR maior que a unidade indica que o setor 'i' de uma dada região - no caso Minas Gerais - apresenta desvantagem competitiva em relação à área de referência, o inverso acontecendo quando o índice é menor do que a unidade.

Esse índice foi calculado para as oito atividades já descritas, comparando- se, com o total do país, as ULs de empresas com mais de 30 pessoas ocupadas no Brasil, o total de Minas Gerais e as ULs do estrato certo ajustado em Minas Gerais. Além disso, para se ter uma visão mais adequada da mudança, apresenta-se também a evolução dos dois componentes do índice, quais sejam, o custo unitário médio e a produtividade média da mão de obra. Os resultados encontramse na Tabela 6.

Alguns pontos merecem estaque:

i. O ICUR para as ULs de empresas com mais de 30 pessoas ocupa-

Tabela 6_ ICUR, 1996 e 2006 - Empresas Brasil com mais de 30 PO, Minas Gerais, Estrato Certo de Minas Gerais ajustado

\begin{tabular}{|c|c|c|c|c|c|c|}
\hline \multirow[b]{2}{*}{ Atividades/Ano/Regiões } & \multicolumn{3}{|c|}{1996} & \multicolumn{3}{|c|}{2006} \\
\hline & $\begin{array}{c}\text { Brasil } \\
+30\end{array}$ & $\begin{array}{l}\text { Minas } \\
\text { Gerais }\end{array}$ & $\begin{array}{c}\text { MG } \\
\text { Estrato } \\
\text { Certo } \\
\text { ajustado }\end{array}$ & $\begin{array}{c}\text { Brasil } \\
+30\end{array}$ & $\begin{array}{l}\text { Minas } \\
\text { Gerais }\end{array}$ & $\begin{array}{c}\text { MG } \\
\text { Estrato } \\
\text { Certo } \\
\text { ajustado }\end{array}$ \\
\hline Alimentos, bebidas e fumo & 0,98 & 0,74 & 0,49 & 0,97 & 0,89 & 0,67 \\
\hline Extrativa & 1,02 & 0,97 & 0,62 & 0,98 & 0,68 & 0,45 \\
\hline Madeira, celulose, edição e móveis & 0,99 & 1,12 & 0,94 & 0,95 & 1,05 & 0,82 \\
\hline Máquinas, equipamentos e veículos & 0,99 & 0,75 & 0,67 & 0,99 & 0,78 & 0,70 \\
\hline Metálicos & 0,98 & 0,88 & 0,76 & 0,95 & 0,81 & 0,69 \\
\hline Não metálicos & 0,98 & 0,82 & 0,69 & 0,95 & 1,02 & 0,85 \\
\hline Petróleo, álcool, farmacêutica e química & 0,99 & 1,03 & 0,77 & 0,98 & 0,87 & 0,67 \\
\hline Têxtil, vestuário, couro e calçados & 0,96 & 0,94 & 0,66 & 0,98 & 1,05 & 0,77 \\
\hline INDÚSTRIA GERAL & 0,98 & 0,87 & 0,68 & 0,97 & 0,83 & 0,66 \\
\hline
\end{tabular}

Fonte: Microdados da PIA/IBGE. Elaboração dos autores. 
das para o Brasil, como era de se esperar, situa-se abaixo da unidade (elas são, portanto, mais competitivas), para 1996 e 2006, com exceção da "indústria extrativa" no início do período. Tal discrepância é decorrente do valor médio das remunerações, muito acima do conjunto dessa atividade, de tal forma que, mesmo a sua maior produtividade, não a tornava mais competitiva.

ii. A produtividade média e a remuneração média dessas ULs situava-se, no início da série, em cerca de $16 \%$ e $14 \%$, respectivamente, acima da média do País para todo o conjunto de unidades produtivas. Em 2006, esses percentuais se ampliaram para 19\% e 15\%, conforme Tabela 7 .

iii. Para o conjunto de unidades produtivas do Estado de Minas Gerais, duas atividades se mostravam menos competitivas que a média nacional em 1996: "Madeira, celulose, edição e móveis" e "Petróleo, álcool, farmacêutica e química". Em ambos, o principal determinante foi a produtividade média, muito abaixo do observado para essas atividades no conjunto do País;

iv. O ICUR, para 2006, nas ULs mineiras, mostrava que quatro grupos de atividades apresentavam menor competitividade: "Têxtil, vestuário, couro e calçados", "Alimentos, bebidas e fumo", "Máquinas, equipamentos e veículos" e "Não metálicos". Tanto a remuneração média quanto a produtividade apresentavam-se abaixo da média do País para as mesmas atividades.

v. Em 1996, somente a indústria mineira de produtos "Metálicos" apresentava remuneração média acima $(11 \%)$ do conjunto do País. Em 2006, essa diferença subiu para 19\% (ver Tabela 7);

vi. Ainda para essas unidades, em 1996, somente dois conjuntos de atividades apresentavam produtividade acima dos setores nacionais correspondentes: indústriadeprodutos "Metálicos" (27\%) e "Não metálicos" (12\%). Em 2006, somente a primeira permaneceu, embora a diferença tenha se amplia-do para $47 \%$; 
Tabela 7_Remuneração média e Produtividade média, Brasil, Empresas com mais de 30 empregados no Brasil, Minas Gerais e Estrato Certo de Minas Gerais, 1996 e 2006 - por atividades selecionadas

\begin{tabular}{|c|c|c|c|c|c|c|c|c|}
\hline \multirow[b]{2}{*}{ Atividades/Ano/Regiões } & \multicolumn{4}{|c|}{1996} & \multicolumn{4}{|c|}{2006} \\
\hline & Brasil & $\begin{array}{c}\text { Brasil } \\
+\mathbf{3 0}\end{array}$ & $\begin{array}{l}\text { Minas } \\
\text { Gerais }\end{array}$ & $\begin{array}{c}\text { MG } \\
\text { Estrato } \\
\text { Certo } \\
\text { ajustado }\end{array}$ & Brasil & $\begin{array}{c}\text { Brasil } \\
+\mathbf{3 0}\end{array}$ & $\begin{array}{l}\text { Minas } \\
\text { Gerais }\end{array}$ & $\begin{array}{c}\text { MG } \\
\text { Estrato } \\
\text { Certo } \\
\text { ajustado }\end{array}$ \\
\hline \multicolumn{9}{|l|}{ Remuneração média (1) } \\
\hline Extrativa & 49,4 & 58,4 & 44,9 & 45,7 & 56,0 & 66,3 & 28,8 & 29,0 \\
\hline Alimentos, bebidas e fumo & 21,7 & 24,5 & 16,0 & 19,9 & 17,8 & 19,5 & 14,6 & 17,5 \\
\hline Têxtil, vestuário, couro e calçados & 14,5 & 16,1 & 10,1 & 12,2 & 12,0 & 13,4 & 8,8 & 10,2 \\
\hline Madeira, celulose, edição e móveis & 22,4 & 27,3 & 16,5 & 22,6 & 19,7 & 24,4 & 13,5 & 18,1 \\
\hline Petróleo, álcool, farmacêutica e química & 39,9 & 43,1 & 24,5 & 25,2 & 38,2 & 42,3 & 21,8 & 23,3 \\
\hline Não metálicos & 20,6 & 25,7 & 18,8 & 23,0 & 18,9 & 24,1 & 18,9 & 26,0 \\
\hline Metálicos & 31,9 & 37,0 & 35,5 & 39,9 & 28,7 & 34,5 & 34,1 & 39,6 \\
\hline Máquinas, equipamentos e veículos & 40,3 & 43,4 & 27,1 & 28,8 & 37,1 & 40,4 & 28,3 & 30,1 \\
\hline INDÚSTRIA GERAL & 27,8 & 31,8 & 22,7 & 26,9 & 25,0 & 28,9 & 20,1 & 24,4 \\
\hline \multicolumn{9}{|l|}{ Produtividade média } \\
\hline Extrativa & 165,2 & 192,1 & 155,1 & 248,2 & 308,9 & 373,3 & 232,3 & 358,8 \\
\hline Alimentos, bebidas e fumo & 75,6 & 87,3 & 75,6 & 140,6 & 67,2 & 75,8 & 62,0 & 98,5 \\
\hline Têxtil, vestuário, couro e calçados & 23,1 & 26,9 & 17,2 & 29,2 & 23,2 & 26,6 & 16,3 & 25,8 \\
\hline Madeira, celulose, edição e móveis & 66,3 & 82,0 & 43,5 & 70,9 & 56,0 & 72,8 & 36,4 & 62,3 \\
\hline Petróleo, álcool, farmacêutica e química & 195,4 & 213,6 & 116,9 & 160,5 & 180,7 & 204,7 & 118,6 & 165,0 \\
\hline Não metálicos & 52,1 & 66,5 & 58,3 & 84,2 & 53,0 & 71,4 & 51,9 & 86,6 \\
\hline Metálicos & 117,0 & 138,1 & 148,4 & 191,8 & 102,2 & 129,5 & 150,2 & 204,5 \\
\hline Máquinas, equipamentos e veículos & 86,9 & 93,9 & 77,7 & 93,0 & 90,3 & 98,7 & 88,1 & 103,9 \\
\hline INDÚSTRIA GERAL & 86,8 & 101,1 & 81,5 & 123,6 & 83,4 & 99,5 & 80,8 & 122,5 \\
\hline
\end{tabular}

(1) Mil reais constantes de 2006 divididos pelo número de pessoas ocupadas.

Fonte: Microdados da PIA/IBGE. Elaboração dos autores.

vii. As ULs do estrato certo de Minas

Gerais eram mais competitivas que a média das empresas com mais de 30 empregados no País, tanto em 1996 quanto em 2006. Também para ambos os anos, 
sete das atividades, à exceção de "Petróleo, álcool, farmacêutica e química", apresentavam produtividade acima da média.

viii. No conjunto, a produtividade dessas unidades se ampliou de $42 \%$ acima da média do País em 1996 para 47\% em 2007. Os salários permaneceram, no conjunto, cerca de $3 \%$ abaixo da média nacional, resultando, então, num índice de competitividade de 0,66 (contra 0,68 em 1996).

\section{6_Competitividade e produtividade das regiões mineiras}

Nesta seção, vamos considerar as oito regiões de Minas Gerais anteriormente definidas para análise. Também se vai utilizar o ICUR para estudar a competitividade relativa das regiões mineiras, tomando como região de referência o Estado de Minas Gerais, e não mais o Brasil. Dessa forma, dado que já foi estabelecida a diferença de comportamento do Estado em relação ao País, vai se estabelecer as diferenças de comportamento das regiões mineiras em relação ao Estado.
Primeiramente, destaca-se a região Central por ser a mais diversificada e a de maior importância na geração do VTI do Estado. Logo após, destacam-se as regiões do Triângulo e Jequitinhonha, Mucuri e Rio Doce, como as duas regiões especializadas. Em seguida, são analisadas as demais regiões.

\section{1_Central}

A região Central representa a principal área industrial mineira. Observa-se que, entre 1996 e 2006, houve perda de importância relativa dessa região quando se analisa o número total de ULs, o total do PO e o total dos salários. Por outro lado, com relação ao VTI, houve aumento de sua participação: de $48,7 \%$ para 55,9\% (Tabela 8).

Essa diferença de comportamento está relacionada ao aumento significativo na produtividade (medida pela relação VTI/PO) nessa região. A Tabela 9 mostra que, enquanto o pessoal ocupado por unidade local caiu de 130 para 125 pessoas, o VTI por trabalhador e por unidade local cresceu significativamente acima da média do Estado. Em 1996, o VTI/PO e o VTI/UL eram, respectivamente, $1 \%$ e $23 \%$ superiores à média estadual, percentuais que saltaram, em 2006, para $35 \%$ e $57 \%$. 
Tabela 8_ Participação percentual das variáveis selecionadas, 1996 e 2006 - atividades e regiões definidas

\begin{tabular}{|c|c|c|c|c|c|c|c|c|c|c|c|c|c|c|c|c|c|c|c|}
\hline \multirow{2}{*}{ Atividades/Regiões/Ano } & \multirow{2}{*}{ Variáveis } & \multicolumn{2}{|c|}{$\begin{array}{c}\text { Alto } \\
\text { Paranaíba }\end{array}$} & \multicolumn{2}{|c|}{ Central } & \multicolumn{2}{|c|}{ Centro Deste } & \multicolumn{2}{|c|}{$\begin{array}{l}\text { Jequetinhonha, } \\
\text { Mucuri e Rio Doce }\end{array}$} & \multicolumn{2}{|c|}{ Zona da Mata } & \multicolumn{2}{|c|}{$\begin{array}{l}\text { Noroeste e } \\
\text { Norte }\end{array}$} & \multicolumn{2}{|c|}{ Sul de Minas } & \multicolumn{2}{|c|}{ Triângulo } & \multicolumn{2}{|c|}{ Total } \\
\hline & & 1996 & 2006 & 1996 & 2006 & 1996 & 2006 & 1996 & 2006 & 1996 & 2006 & 1996 & 2006 & 1996 & 2006 & 1996 & 2006 & 1996 & 2006 \\
\hline \multirow{4}{*}{ Alimentos, bebidas e fumo } & UL & 32,3 & 23,6 & 13,1 & 11,6 & 16,9 & 8,9 & 47,3 & 20,7 & 26,4 & 14,6 & 26,4 & 18,6 & 31,4 & 14,9 & 36,7 & 29,5 & 23,3 & 14,5 \\
\hline & $\mathrm{PO}$ & 27,2 & 29,8 & 8,4 & 9,6 & 19,8 & 13,4 & 14,8 & 14,4 & 20,6 & 19,3 & 11,7 & 11,7 & 24,3 & 18,3 & 44,1 & 67,6 & 16,0 & 18,6 \\
\hline & Salários & 37,5 & 24,7 & 4,9 & 5,6 & 22,6 & 15,3 & 5,1 & 6,1 & 17,0 & 12,8 & 17,0 & 9,7 & 22,5 & 16,7 & 52,3 & 65,9 & 12,0 & 13,5 \\
\hline & VTI & 28,4 & 24,2 & 7,8 & 5,4 & 38,0 & 17,6 & 9,3 & 2,8 & 23,5 & 12,2 & 16,4 & 7,5 & 39,0 & 26,9 & 73,1 & 75,0 & 22,9 & 15,2 \\
\hline \multirow{4}{*}{ Extrativa } & UL & 7,2 & 5,8 & 10,6 & 8,0 & 12,0 & 6,3 & 9,9 & 10,8 & 3,6 & 5,6 & 10,9 & 4,6 & 11,6 & 14,1 & 2,9 & 2,5 & 9,3 & 8,2 \\
\hline & $\mathrm{PO}$ & 8,7 & 5,2 & 9,7 & 9,6 & 4,8 & 2,3 & 3,4 & 2,4 & 1,9 & 1,2 & 6,6 & 1,4 & 2,7 & 3,6 & 0,5 & 0,4 & 6,3 & 5,3 \\
\hline & Salários & 14,3 & 10,6 & 17,8 & 11,0 & 8,7 & 3,7 & 1,2 & 1,2 & 2,0 & 1,2 & 10,2 & 1,5 & 2,2 & 3,3 & 0,4 & 0,2 & 11,2 & 6,8 \\
\hline & VTI & 8,3 & 1,0 & 17,7 & 25,6 & 10,9 & 4,3 & 1,0 & 0,9 & 1,9 & 3,6 & 4,0 & 0,9 & 2,0 & 3,7 & 0,1 & 0,1 & 9,8 & 15,1 \\
\hline \multirow{4}{*}{$\begin{array}{l}\text { Madeira, celulose, } \\
\text { edição e móveis }\end{array}$} & $\mathrm{UL}$ & 5,9 & 15,7 & 11,0 & 10,7 & 6,2 & 6,5 & 7,1 & 7,1 & 19,6 & 21,4 & 2,1 & 6,8 & 7,6 & 6,8 & 7,6 & 9,3 & 9,9 & 10,3 \\
\hline & $\mathrm{PO}$ & 10,5 & 18,0 & 7,4 & 6,1 & 6,1 & 4,9 & 6,6 & 6,6 & 22,6 & 25,9 & 1,1 & 3,0 & 6,2 & 5,4 & 6,5 & 4,5 & 8,3 & 7,7 \\
\hline & Salários & 1,9 & 10,9 & 5,9 & 4,2 & 3,2 & 3,8 & 9,7 & 8,0 & 16,9 & 19,8 & 0,5 & 1,6 & 5,0 & 4,2 & 5,2 & 4,9 & 6,6 & 5,7 \\
\hline & VTI & 1,0 & 2,8 & 5,0 & 1,8 & 2,0 & 3,0 & 10,9 & 10,9 & 15,1 & 14,3 & 0,7 & 1,0 & 4,5 & 3,2 & 1,7 & 3,2 & 5,4 & 3,8 \\
\hline \multirow{4}{*}{$\begin{array}{l}\text { Máquinas, equipamentos } \\
\text { e veículos }\end{array}$} & UL & 5,0 & 4,4 & 15,5 & 19,3 & 3,8 & 2,8 & 6,1 & 6,4 & 5,9 & 5,6 & 1,9 & 4,6 & 12,8 & 15,2 & 9,0 & 8,2 & 10,5 & 12,0 \\
\hline & $\mathrm{PO}$ & 2,2 & 2,2 & 26,5 & 30,5 & 3,4 & 2,5 & 9,5 & 12,9 & 8,1 & 8,5 & 2,4 & 9,8 & 27,2 & 30,4 & 7,8 & 4,7 & 18,9 & 20,6 \\
\hline & Salários & 0,8 & 1,9 & 28,7 & 35,2 & 2,8 & 2,8 & 4,3 & 7,3 & 8,9 & 20,7 & 2,6 & 12,3 & 29,2 & 39,8 & 6,4 & 5,5 & 20,7 & 26,5 \\
\hline & VTI & 0,4 & 0,5 & 31,0 & 25,5 & 1,9 & 3,3 & 2,6 & 2,0 & 5,3 & 6,7 & 2,3 & 8,0 & 19,4 & 33,0 & 3,9 & 2,3 & 18,6 & 18,6 \\
\hline \multirow{4}{*}{ Metálicos } & UL & 4,6 & 5,9 & 16,0 & 16,8 & 14,9 & 15,1 & 5,7 & 13,9 & 5,1 & 3,4 & 8,0 & 5,6 & 5,0 & 5,3 & 5,0 & 7,1 & 10,6 & 11,2 \\
\hline & $\mathrm{PO}$ & 7,1 & 6,8 & 19,8 & 19,3 & 20,1 & 19,3 & 57,0 & 44,2 & 8,0 & 5,8 & 18,7 & 9,6 & 8,8 & 5,1 & 2,6 & 2,3 & 18,8 & 15,1 \\
\hline & Salários & 21,6 & 25,3 & 22,5 & 24,3 & 26,0 & 29,5 & 76,2 & 68,3 & 25,8 & 20,7 & 24,3 & 16,0 & 15,6 & 8,6 & 1,7 & 1,9 & 28,0 & 24,6 \\
\hline & VTI & 39,7 & 58,7 & 17,8 & 20,0 & 21,2 & 30,1 & 72,8 & 77,6 & 27,8 & 50,1 & 23,0 & 20,4 & 17,6 & 10,6 & 0,9 & 1,1 & 23,2 & 26,6 \\
\hline \multirow{4}{*}{ Não metálicos } & UL & 27,5 & 22,5 & 9,2 & 7,9 & 6,4 & 6,5 & 9,7 & 16,7 & 4,7 & 4,5 & 13,0 & 12,6 & 6,0 & 5,3 & 11,9 & 11,7 & 8,9 & 8,2 \\
\hline & $\mathrm{PO}$ & 26,9 & 20,3 & 6,9 & 5,9 & 3,9 & 4,4 & 3,4 & 6,0 & 1,6 & 1,9 & 8,5 & 8,1 & 5,4 & 4,3 & 5,3 & 3,3 & 6,0 & 5,3 \\
\hline & Salários & 6,1 & 7,5 & 6,4 & 7,3 & 5,1 & 6,7 & 1,0 & 2,5 & 0,9 & 1,1 & 6,3 & 5,1 & 6,4 & 5,4 & 2,8 & 1,7 & 5,1 & 5,6 \\
\hline & VTI & 5,1 & 1,9 & 7,4 & 4,7 & 3,3 & 12,6 & 1,4 & 1,3 & 0,6 & 0,6 & 6,7 & 2,8 & 5,7 & 4,8 & 0,8 & 0,6 & 5,0 & 3,8 \\
\hline \multirow{4}{*}{$\begin{array}{l}\text { Petróleo, álcool, } \\
\text { farmacêutica e química }\end{array}$} & UL & 8,9 & 5,8 & 9,5 & 12,2 & 10,4 & 11,3 & 6,3 & 11,9 & 6,2 & 7,4 & 26,5 & 37,4 & 5,9 & 8,3 & 13,9 & 15,0 & 9,5 & 11,8 \\
\hline & $\mathrm{PO}$ & 11,0 & 6,9 & 7,2 & 8,8 & 10,9 & 12,2 & 1,9 & 8,3 & 5,7 & 6,8 & 23,3 & 28,9 & 9,0 & 10,3 & 21,3 & 8,7 & 8,9 & 9,9 \\
\hline & Salários & 16,1 & 14,2 & 7,5 & 8,0 & 8,5 & 12,1 & 1,4 & 4,9 & 7,3 & 6,8 & 20,5 & 32,1 & 11,5 & 12,0 & 23,8 & 14,7 & 8,7 & 9,8 \\
\hline & VTI & 16,3 & 9,9 & 8,7 & 15,3 & 6,3 & 11,9 & 1,1 & 3,7 & 8,3 & 3,9 & 26,5 & 34,9 & 7,1 & 11,6 & 16,5 & 16,0 & 9,4 & 13,3 \\
\hline \multirow{4}{*}{$\begin{array}{l}\text { Têxtil, vestuário, } \\
\text { couro e calçados }\end{array}$} & UL & 8,7 & 16,3 & 14,9 & 12,5 & 29,4 & 42,6 & 7,2 & 11,0 & 28,4 & 37,0 & 11,3 & 9,8 & 19,5 & 29,8 & 13,0 & 16,0 & 17,7 & 23,2 \\
\hline & $\mathrm{PO}$ & 6,4 & 10,7 & 14,0 & 10,0 & 30,9 & 41,0 & 2,7 & 4,0 & 31,3 & 30,7 & 27,6 & 27,6 & 16,5 & 22,5 & 12,0 & 8,4 & 16,6 & 17,2 \\
\hline & Salários & 1,6 & 4,9 & 6,0 & 4,1 & 23,1 & 26,0 & 0,5 & 0,9 & 21,3 & 16,9 & 18,6 & 21,7 & 7,6 & 10,0 & 7,5 & 5,2 & 7,5 & 7,3 \\
\hline & VTI & 0,8 & 1,0 & 4,4 & 1,6 & 16,3 & 17,1 & 0,5 & 0,3 & 17,3 & 8,6 & 20,3 & 24,6 & 4,7 & 6,3 & 3,1 & 1,7 & 5,5 & 3,3 \\
\hline \multirow{4}{*}{ INDÚSTRIA GERAL } & UL & 3,4 & 2,9 & 39,5 & 35,5 & 10,8 & 14,5 & 6,6 & 5,6 & 16,4 & 8,7 & 4,6 & 4,1 & 14,8 & 18,9 & 8,1 & 6,8 & 100,0 & 100,0 \\
\hline & $\mathrm{PO}$ & 1,8 & 2,3 & 48,1 & 41,4 & 6,9 & 9,6 & 8,3 & 7,1 & 13,2 & 7,0 & 4,6 & 4,2 & 13,5 & 16,7 & 6,8 & 9,2 & 100,0 & 100,0 \\
\hline & Salários & 1,7 & 1,8 & 55,0 & 51,2 & 3,7 & 5,4 & 13,3 & 10,2 & 16,5 & 2,5 & 3,2 & 3,2 & 5,5 & 13,5 & 5,8 & 8,1 & 100,0 & 100,0 \\
\hline & VTI & 2,0 & 2,4 & 48,7 & 55,9 & 3,8 & 3,2 & 11,5 & 11,3 & 21,0 & 1,4 & 3,7 & 2,4 & 11,7 & 9,9 & 13,0 & 9,7 & 100,0 & 100,0 \\
\hline
\end{tabular}

Fonte: Microdados da PIA/IBGE. Elaboração dos autores. 
Tabela 9_ Indicadores PO/UL, VTI/PO e PO/UL, 1996 e 2006 - por atividade e região selecionadas - Velores do VIT em mil R\$ e deflacionados pelo IPCA

(continua)

\begin{tabular}{|c|c|c|c|c|c|c|c|c|c|c|c|}
\hline \multirow{2}{*}{$\begin{array}{l}\text { Atividades/Variáveis } \\
\text { Regiốes/Ano }\end{array}$} & & \multicolumn{2}{|c|}{ Alto Paranaíba } & \multicolumn{2}{|c|}{ Central } & \multicolumn{2}{|c|}{ Centro-Oeste } & \multicolumn{2}{|c|}{$\begin{array}{l}\text { Jquetitinhonha, } \\
\text { Mucuri e Rio Doce }\end{array}$} & \multicolumn{2}{|c|}{ Zona da Mata } \\
\hline & & 1996 & 2006 & 1996 & 2006 & 1996 & 2006 & 1996 & 2006 & 1996 & 2006 \\
\hline \multirow{3}{*}{$\begin{array}{l}\text { Alimentos,bebidas } \\
\text { e fumo }\end{array}$} & $\mathrm{PO} / \mathrm{UL}$ & 49,3 & 109,3 & 83,7 & 103,4 & 79,9 & 107,3 & 42,2 & 94,6 & 67,5 & 113,1 \\
\hline & VT I/PO & 42,9 & 90,0 & 35,4 & 80,9 & 39,5 & 46,8 & 32,6 & 33,4 & 24,3 & 37,9 \\
\hline & VT I/UL & $2.115,4$ & $9.843,7$ & $2.964,8$ & $8.364,5$ & $3.155,0$ & $5.023,8$ & $1.376,8$ & $3.160,3$ & $1.640,3$ & $4.281,4$ \\
\hline \multirow{3}{*}{ Extrativa } & $\mathrm{PO} / \mathrm{UL}$ & 70,7 & 77,9 & 118,4 & 149,7 & 27,3 & 25,4 & 45,8 & 30,4 & 44,7 & 18,4 \\
\hline & VT I/PO & 394,6 & 220,5 & 694,4 & $3.863,3$ & 469,7 & 685,4 & 150,2 & 616,4 & 220,9 & $1.807,4$ \\
\hline & VT I/UL & $2.788,7$ & $1.718,0$ & $8.221,9$ & $57.818,7$ & $1.283,2$ & $1.742,1$ & 688,4 & $1.872,5$ & 988,1 & $3.318,5$ \\
\hline \multirow{3}{*}{$\begin{array}{l}\text { Madeira, celulose, } \\
\text { edição e móveis }\end{array}$} & $\mathrm{PO} / \mathrm{UL}$ & 104,0 & 99,1 & 87,7 & 70,6 & 67,3 & 54,1 & 125,7 & 125,5 & 99,8 & 104,1 \\
\hline & VT I/PO & 4,0 & 17,2 & 25,4 & 43,1 & 6,8 & 21,4 & 85,9 & 280,4 & 14,2 & 32,9 \\
\hline & VT I/UL & 420,5 & $1.708,5$ & $2.231,9$ & $3.040,4$ & 455,7 & $1.156,0$ & $10.799,3$ & $35.206,6$ & $1.419,0$ & $3.426,2$ \\
\hline \multirow{3}{*}{$\begin{array}{l}\text { Máquinas, equipamentos e } \\
\text { veículos }\end{array}$} & $\mathrm{PO} / \mathrm{UL}$ & 25,5 & 43,0 & 221,8 & 197,6 & 61,3 & 64,0 & 211,7 & 272,9 & 118,9 & 130,7 \\
\hline & VT I/PO & 7,3 & 23,5 & 44,5 & 120,9 & 11,4 & 48,2 & 14,3 & 26,9 & 14,0 & 47,3 \\
\hline & VT I/UL & 187,1 & $1.009,7$ & $9.870,7$ & $23.891,4$ & 698,8 & $3.083,2$ & $3.020,1$ & $7.350,1$ & $1.670,8$ & $6.185,9$ \\
\hline \multirow{3}{*}{ Metálicos } & $\mathrm{PO} / \mathrm{UL}$ & 90,0 & 98,9 & 160,4 & 143,3 & 92,0 & 91,2 & $1.357,5$ & 431,6 & 137,2 & 144,1 \\
\hline & VT I/PO & 7,3 & 23,5 & 44,5 & 120,9 & 11,4 & 48,2 & 14,3 & 26,9 & 14,0 & 47,3 \\
\hline & VT I/UL & $20.759,5$ & $94.912,6$ & $5.485,8$ & $21.492,0$ & $2.005,0$ & $5.086,4$ & $90.030,8$ & $128.706,4$ & $10.116,4$ & $74.684,9$ \\
\hline \multirow{3}{*}{ Não metálicos } & $\mathrm{PO} / \mathrm{UL}$ & 57,0 & 77,9 & 96,7 & 92,8 & 41,7 & 48,9 & 47,6 & 48,9 & 29,7 & 35,5 \\
\hline & VT I/PO & 7,9 & 10,4 & 41,0 & 114,5 & 17,5 & 101,5 & 21,8 & 37,6 & 8,0 & 19,2 \\
\hline & VT I/UL & 445,8 & 807,6 & $3.960,1$ & $10.632,1$ & 731,6 & $4.962,5$ & $1.040,0$ & $1.839,1$ & 237,3 & 680,2 \\
\hline \multirow{3}{*}{$\begin{array}{l}\text { Petróleo, álcool, } \\
\text { farmacêutica e química }\end{array}$} & $\mathrm{PO} / \mathrm{UL}$ & 72,2 & 102,5 & 99,0 & 90,0 & 71,6 & 77,2 & 41,2 & 94,7 & 79,5 & 78,9 \\
\hline & VT I/PO & 60,9 & 158,3 & 46,0 & 251,7 & 12,0 & 35,0 & 29,4 & 75,4 & 31,2 & 34,0 \\
\hline & VT I/UL & $4.399,6$ & $16.220,0$ & $4.551,0$ & $22.649,6$ & 858,2 & $2.698,7$ & $1.212,6$ & $7.139,3$ & $2.483,0$ & $2.680,8$ \\
\hline \multirow{3}{*}{$\begin{array}{l}\text { Têxtil, vestuário, } \\
\text { couro e calçados }\end{array}$} & $\mathrm{PO} / \mathrm{UL}$ & 42,9 & 57,0 & 121,9 & 99,2 & 71,9 & 68,8 & 50,4 & 49,2 & 95,0 & 71,2 \\
\hline & VT I/PO & 4,9 & 10,8 & 12,1 & 23,0 & 10,9 & 14,9 & 10,2 & 11,8 & 11,8 & 16,8 \\
\hline & VT I/UL & 208,5 & 614,7 & $1.476,2$ & $2.282,1$ & 781,5 & $1.024,9$ & 516,6 & 582,5 & $1.119,9$ & $1.196,1$ \\
\hline \multirow{3}{*}{ Média Regional } & $\mathrm{PO} / \mathrm{UL}$ & 58,3 & 86,4 & 129,9 & 125,0 & 68,3 & 71,4 & 134,6 & 135,6 & 86,2 & 85,9 \\
\hline & VT I/PO & 41,2 & 111,0 & 38,0 & 144,3 & 20,6 & 35,7 & 51,9 & 170,0 & 21,3 & 59,7 \\
\hline & VT I/UL & $2.402,7$ & $9.587,7$ & $4.936,7$ & $18.046,1$ & $1.407,2$ & $2.549,5$ & $6.991,7$ & $23.055,9$ & $1.838,0$ & $5.129,4$ \\
\hline
\end{tabular}


Tabela 9_ Indicadores PO/UL, VTI/PO e PO/UL, 1996 e 2006 - por atividade e regiáo selecionadas - Velores do VIT em mil R\$ e deflacionados pelo IPCA

[conclusão]

\begin{tabular}{|c|c|c|c|c|c|c|c|c|c|c|c|}
\hline \multirow{2}{*}{\multicolumn{2}{|c|}{$\begin{array}{l}\text { Atidaudes/Variáveis } \\
\text { Regiões/Ano }\end{array}$}} & \multicolumn{2}{|c|}{ Zona da Mata } & \multicolumn{2}{|c|}{ Noroeste e Norte } & \multicolumn{2}{|c|}{ Sul de Minas } & \multicolumn{2}{|c|}{ Triângulo } & \multicolumn{2}{|c|}{ Total } \\
\hline & & 1996 & 2006 & 1996 & 2006 & 1996 & 2006 & 1996 & 2006 & 1996 & 2006 \\
\hline \multirow{3}{*}{$\begin{array}{l}\text { Alimentos,bebidas } \\
\text { e fumo }\end{array}$} & PO/UL & 67,5 & 113,1 & 47,3 & 68,7 & 75,4 & 117,1 & 107,4 & 333,9 & 73,4 & 137,0 \\
\hline & VT I/PO & 24,3 & 37,9 & 42,3 & 38,9 & 52,2 & 92,8 & 118,9 & 125,3 & 53,7 & 87,8 \\
\hline & VT I/UL & $1.640,3$ & $4.281,4$ & $2.002,6$ & $2.670,5$ & $3.930,8$ & $10.872,7$ & $12.761,5$ & $41.848,2$ & $3.941,4$ & $12.029,2$ \\
\hline \multirow{3}{*}{ Extrativa } & $\mathrm{PO} / \mathrm{UL}$ & 44,7 & 18,4 & 64,8 & 32,5 & 22,9 & 23,9 & 15,5 & 25,6 & 72,7 & 68,9 \\
\hline & VT I/PO & 220,9 & $1.807,4$ & 182,2 & 393,2 & 239,7 & 652,5 & 90,0 & 186,8 & 582,5 & $3.071,9$ \\
\hline & VT I/UL & 988,1 & $3.318,5$ & $1.180,7$ & $1.277,3$ & 549,8 & $1.557,4$ & 139,4 & 478,9 & $4.237,1$ & $21.172,5$ \\
\hline \multirow{3}{*}{$\begin{array}{l}\text { Madeira, celulose, } \\
\text { edição e móveis }\end{array}$} & $\mathrm{PO} / \mathrm{UL}$ & 99,8 & 104,1 & 56,6 & 48,1 & 79,4 & 75,0 & 76,0 & 70,3 & 89,4 & 80,5 \\
\hline & VT I/PO & 14,2 & 32,9 & 18,5 & 19,4 & 23,5 & 37,1 & 19,1 & 80,0 & 24,4 & 52,5 \\
\hline & VT I/UL & $1.419,0$ & $3.426,2$ & $1.047,1$ & 935,2 & $1.869,5$ & $2.781,9$ & $1.450,4$ & $5.624,5$ & $2.180,5$ & $4.225,2$ \\
\hline \multirow{3}{*}{$\begin{array}{l}\text { Máquinas, equipa- } \\
\text { mentos e veículos }\end{array}$} & $\mathrm{PO} / \mathrm{UL}$ & 118,9 & 130,7 & 133,7 & 232,1 & 206,4 & 189,4 & 77,4 & 83,8 & 191,5 & 183,5 \\
\hline & VT I/PO & 14,0 & 47,3 & 29,2 & 49,4 & 23,1 & 68,5 & 36,0 & 56,1 & 37,0 & 97,0 \\
\hline & VT I/UL & $1.670,8$ & $6.185,9$ & $3.900,3$ & $11.462,8$ & $4.775,6$ & $12.974,8$ & $2.787,3$ & $4.698,1$ & $7.080,9$ & $17.802,9$ \\
\hline \multirow{3}{*}{ Metálicos } & PO/UL & 137,2 & 144,1 & 250,9 & 185,0 & 170,0 & 91,1 & 45,3 & 47,0 & 189,1 & 144,7 \\
\hline & VT I/PO & 14,0 & 47,3 & 29,2 & 49,4 & 23,1 & 68,5 & 36,0 & 56,1 & 37,0 & 97,0 \\
\hline & VT I/UL & $10.116,4$ & $74.684,9$ & $9.251,9$ & $23.850,7$ & $11.045,1$ & $12.121,8$ & $1.116,4$ & $2.607,8$ & $8.773,2$ & $27.207,9$ \\
\hline \multirow{3}{*}{ não metálicos } & $\mathrm{PO} / \mathrm{UL}$ & 29,7 & 35,5 & 70,4 & 69,5 & 87,4 & 76,9 & 40,0 & 41,4 & 71,7 & 69,5 \\
\hline & VT I/PO & 8,0 & 19,2 & 23,7 & 20,8 & 34,1 & 71,0 & 10,4 & 20,4 & 31,6 & 77,6 \\
\hline & VT I/UL & 237,3 & 680,2 & $1.669,4$ & $1.447,2$ & $2.978,8$ & $5.456,5$ & 418,4 & 846,0 & $2.263,6$ & $5.393,6$ \\
\hline \multirow{3}{*}{$\begin{array}{l}\text { Petróleo, álcool, far- } \\
\text { macêutica e química }\end{array}$} & $\mathrm{PO} / \mathrm{UL}$ & 79,5 & 78,9 & 94,1 & 84,2 & 149,2 & 118,1 & 136,7 & 84,6 & 99,3 & 90,4 \\
\hline & VT I/PO & 31,2 & 34,0 & 34,1 & 72,9 & 25,8 & 71,1 & 55,6 & 208,2 & 39,6 & 143,5 \\
\hline & VT I/UL & $2.483,0$ & $2.680,8$ & $3.215,1$ & $6.141,2$ & $3.852,4$ & $8.399,7$ & $7.598,1$ & $17.601,5$ & $3.931,8$ & $12.964,7$ \\
\hline \multirow{3}{*}{$\begin{array}{l}\text { Textil, vestuário, } \\
\text { couro e calçados }\end{array}$} & $\mathrm{PO} / \mathrm{UL}$ & 95,0 & 71,2 & 260,6 & 308,5 & 82,6 & 71,6 & 82,1 & 76,3 & 99,9 & 79,5 \\
\hline & VT I/PO & 11,8 & 16,8 & 22,1 & 53,8 & 9,2 & 17,6 & 18,5 & 22,9 & 12,5 & 20,6 \\
\hline & VT I/UL & $1.119,9$ & $1.196,1$ & $5.753,8$ & $16.609,7$ & 763,4 & $1.260,0$ & $1.515,5$ & 1. 745,9 & 1. 249,3 & $1.640,1$ \\
\hline \multirow{3}{*}{ Média Regional } & $\mathrm{PO} / \mathrm{UL}$ & 86,2 & 85,9 & 106,9 & 109,0 & 97,5 & 94,9 & 89,3 & 146,0 & 106,7 & 107,2 \\
\hline & VT I/PO & 21,3 & 59,7 & 30,0 & 60,5 & 32,4 & 63,2 & 71,7 & 113,0 & 37,5 & 107,0 \\
\hline & VT I/UL & $1.838,0$ & $5.129,4$ & $3.210,8$ & $6.590,5$ & $3.163,8$ & $5.999,3$ & $6.402,1$ & $16.490,9$ & 4. 005,2 & $11.476,9$ \\
\hline
\end{tabular}

Fonte: Microdados da PIA/ IBGE. Elaboração dos autores. 
Considerando o período de análise e as atividades selecionadas, nota-se que ocorreu na região um crescimento da participação relativa das atividades "Extrativa", "Metálicos" e "Petróleo, álcool, farmacêutica e química". Todas as outras atividades tiveram queda na participação percentual no VTI no ano de $2006 \mathrm{em}$ comparação a 1996.

A atividade "Extrativa" aumentou em termos relativos sua produtividade (VTI/PO), tanto em relação à média regional quanto em relação à média estadual global e da atividade. O tamanho médio das ULs, utilizando o indicador PO/ UL, passou de 118 para 150. Dado que a atividade "Extrativa" mineira tem maior representatividade na região Central, a redução do emprego e da massa salarial observada no Estado para essa atividade é corroborado pelo comportamento dessa atividade na região Central.

O inverso ocorreu para o grupamento de atividade denominado "Máquinas, equipamentos e veículos": o tamanho médio das ULs produtivas reduziu-se de 222 para 198, enquanto a relação da produtividade média do trabalho dessa atividade com a média regional reduziu-se de 1,2 para 0,8 vez.
Os dois outros grupos de atividades com presença significativa na região - "Metálicos" e "Petróleo, álcool, farmacêutica e química" - aumentaram sua participação no VTI industrial regional, comportamento semelhante ao verificado para os demais indicadores.

Três dessas atividades destacam-se novamente quando o indicador analisado é o ICUR. Das oito atividades analisadas, elas apresentaram redução no índice em 2006, o que indica aumento relativo na competitividade potencial dos setores: "Extrativa", "Petróleo, álcool, farmacêutica e química", "Metálicos". A atividade com maior redução no ICUR foi "Petróleo, álcool, farmacêutica e química", com -34\%. Nessa atividade, houve queda na remuneração do fator trabalho e aumento da produtividade, sendo este último mais expressivo. A "Extrativa" apresentou queda de 33\% no ICUR, com crescimento da produtividade acima de média da indústria na região e queda de $40 \%$ na remuneração do fator trabalho. O ICUR da atividade "Metálicos" apresentou queda de $0,5 \%$, resultante do crescimento do custo do fator trabalho abaixo do crescimento da produtividade. 
${ }_{10}$ Ou seja, repetem-se as mesmas atividades em 2006, mesmo quando houve mudança na estrutura regional em favor de outras atividades.

11 Em estudos adicionais, seria interessante buscar os fatores que determinaram esse comportamento no período analisado. Uma das hipóteses a ser testada seria a entrada de novas empresas no setor, menores e menos produtivas.

\section{2_As duas regióes especializadas do Estado}

Observando a Tabela 11, a seguir, onde está a participação percentual acumulada do VTI nas duas, três e quatro principais atividades de cada região de análise, os resultados mostram as atividades com maior presença na economia regional, tomando como base o ano de $1996 .{ }^{10}$

Nas regiões do Alto Paranaíba, Central, Noroeste/Norte e Zona da Mata, observou-se aumento na participação das quatro principais atividades no VTI, em 2006. O inverso ocorreu nas outras regiões.

Considerando os dados do VTI regional, das oito regiões adotadas para a análise no presente trabalho, pode-se dizer que duas são especializadas. Nelas mais de $2 / 3$ do VTI industrial originase em um único grupamento de atividades: a região do Triângulo, especializada na atividade de "Alimentos, bebidas e fumo" (73\% e 75\% do VTI regional em 1996 e 2006, respectivamente), e a região do "Jequitinhonha, Mucuri e Rio Doce", especializada nas atividades denominada de "Metálicos", que engloba toda a metalurgia e a siderurgia.

A atividade de "Alimentos, bebidas e fumo" responde pelo maior per- centual de todas as variáveis selecionadas na região do Triângulo, com destaque para a participação do VTI. Entretanto, observando o ICUR para essa atividade, nota-se que houve um decréscimo relativo da competitividade potencial. Os indicadores VTI/UL, VTI/PO e PO/UL auxiliam na compreensão do comportamento do ICUR. Enquanto o VTI/UL, que era 3,2 vezes a média estadual da atividade, saltou para 3,5 vezes em 2006, os outros dois indicadores, VTI/PO e PO/ $\mathrm{UL}$, sinalizam que houve um aumento relativo de pessoal ocupado na atividade da região em relação à média do restante do Estado. Dessa forma, o VTI/ PO apresentou uma diminuição de 2,2 vezes em relação à média do Estado em 1996 para 1,4 vez em 2006 e o PO/UL saltou de 1,5 vez a média do Estado para 2,4 vezes. ${ }^{11}$

A segunda atividade em importância na região do Triângulo - "Petróleo, álcool, farmacêutica e química" também tem ligação importante com a agroindústria, com destaque para a produção de álcool. Sua participação no VTI industrial regional se manteve constante nos dois períodos analisados, mas a participação no pessoal ocupado diminuiu significativamente (de 21\% para 9\%). Observando o ICUR, nota-se que houve 
Tabela 10_ ICUR, 1996 e 2006 - por regiões agregadas de Minas Gerais e atividades

\begin{tabular}{|c|c|c|c|c|c|c|c|c|c|c|}
\hline Atividades/Regióes & MG & $\begin{array}{c}\text { Alto } \\
\text { Paranaiba }\end{array}$ & Central & $\begin{array}{c}\text { Centro- } \\
\text { Oeste } \\
\text { de Minas }\end{array}$ & $\begin{array}{c}\text { Zona da } \\
\text { Mata }\end{array}$ & $\begin{array}{l}\text { Sul de } \\
\text { Minas }\end{array}$ & Triângulo & $\begin{array}{l}\text { Jequetinhonha } \\
\text { Mucuri e } \\
\text { Rio Doce }\end{array}$ & $\begin{array}{l}\text { Norte + } \\
\text { Noroeste } \\
\text { de Minas }\end{array}$ & $\begin{array}{c}\text { MG } \\
\text { estrato } \\
\text { certo }\end{array}$ \\
\hline \multicolumn{11}{|l|}{1996} \\
\hline Alimentos, bebidas e fumo & 0,7 & 0,9 & 0,6 & 0,4 & 0,7 & 0,4 & 0,4 & 0,5 & 0,8 & 0,5 \\
\hline Extrativa & 1,0 & 0,9 & 0,6 & 0,5 & 0,6 & 0,6 & 0,9 & 0,7 & 0,8 & 0,6 \\
\hline Madeira, celulose, edição e móveis & 1,1 & 1,4 & 1,0 & 1,3 & 1,0 & 0,9 & 0,8 & 0,8 & 0,6 & 0,9 \\
\hline Máquinas, equipamentos e veículos & 0,8 & 0,6 & 0,6 & 0,8 & 1,4 & 0,7 & 0,4 & 1,1 & 0,7 & 0,7 \\
\hline Metálicos & 0,9 & 0,3 & 0,9 & 0,7 & 0,7 & 0,6 & 0,6 & 0,8 & 0,6 & 0,8 \\
\hline Não metálicos & 0,8 & 0,7 & 0,7 & 0,9 & 0,9 & 0,8 & 1,2 & 0,6 & 0,6 & 0,7 \\
\hline Petróleo, álcool, farmacêutica e química & 1,0 & 0,8 & 0,7 & 1,4 & 0,7 & 1,5 & 0,6 & 1,3 & 0,8 & 0,8 \\
\hline Têxtil, vestuário, couro e calçados & 0,9 & 1,1 & 0,7 & 0,7 & 0,8 & 0,8 & 0,6 & 0,7 & 0,4 & 0,7 \\
\hline INDÚSTRIA GERAL & 0,9 & 0,5 & 0,7 & 0,6 & 0,8 & 0,7 & 0,4 & 0,7 & 0,6 & 0,7 \\
\hline \multicolumn{11}{|l|}{2006} \\
\hline Alimentos, bebidas e fumo & 0,9 & 0,6 & 0,7 & 1,1 & 1,0 & 0,6 & 0,6 & 1,3 & 0,7 & 0,7 \\
\hline Extrativa & 0,7 & 2,8 & 0,4 & 1,1 & 0,4 & 1,1 & 2,3 & 1,3 & 2,2 & 0,4 \\
\hline Madeira, celulose, edição e móveis & 1,1 & 1,6 & 1,2 & 1,2 & 1,0 & 1,0 & 0,6 & 0,4 & 1,1 & 0,8 \\
\hline Máquinas, equipamentos e veículos & 0,8 & 1,5 & 0,6 & 0,7 & 1,2 & 0,8 & 1,0 & 1,7 & 1,1 & 0,7 \\
\hline Metálicos & 0,8 & 0,3 & 0,8 & 1,2 & 0,4 & 0,8 & 1,0 & 0,6 & 0,8 & 0,7 \\
\hline Não metálicos & 1,0 & 1,7 & 0,8 & 0,5 & 1,1 & 0,9 & 1,2 & 0,9 & 1,4 & 0,8 \\
\hline Petróleo, álcool, farmacêutica e química & 0,9 & 1,1 & 0,5 & 1,5 & 1,7 & 1,3 & 0,6 & 0,7 & 1,2 & 0,7 \\
\hline Têxtil, vestuário, couro e calçados & 1,1 & 1,2 & 0,8 & 0,9 & 1,0 & 0,7 & 0,8 & 1,0 & 0,5 & 0,8 \\
\hline INDÚSTRIA GERAL & 0,8 & 0,5 & 0,6 & 1,1 & 0,7 & 0,9 & 0,6 & 0,6 & 0,9 & 0,7 \\
\hline
\end{tabular}

Fonte: Microdados da PIA/IBGE. Elaboração dos autores. 
Tabela 11_Participação no VTI regional das maiores atividades, 1996 e 2006 - regiões de Minas

\begin{tabular}{l|c|c|c|c|c|c|c|c}
\multicolumn{1}{c}{ Atividade/Ano } & \multicolumn{2}{c}{$\begin{array}{c}\text { Principal } \\
\text { atividade }\end{array}$} & \multicolumn{2}{c}{$\begin{array}{c}\text { Duas } \\
\text { principais }\end{array}$} & \multicolumn{2}{c|}{$\begin{array}{c}\text { Três } \\
\text { principais }\end{array}$} & \multicolumn{2}{c}{$\begin{array}{c}\text { Quatro } \\
\text { principais }\end{array}$} \\
\cline { 2 - 9 } & $\mathbf{1 9 9 6}$ & $\mathbf{2 0 0 6}$ & $\mathbf{1 9 9 6}$ & $\mathbf{2 0 0 6}$ & $\mathbf{1 9 9 6}$ & $\mathbf{2 0 0 6}$ & $\mathbf{1 9 9 6}$ & $\mathbf{2 0 0 6}$ \\
\hline Alto Paranaíba & 39,7 & 58,7 & 68,1 & 82,9 & 84,4 & 92,8 & 92,7 & 93,8 \\
\hline Central & 31,0 & 25,5 & 48,9 & 45,6 & 66,6 & 71,2 & 75,3 & 86,5 \\
\hline Centro Oeste & 38,0 & 17,6 & 59,2 & 47,7 & 75,5 & 64,8 & 86,4 & 69,2 \\
\hline Jequitinhonha, Mucuri, Rio Doce & 72,8 & 77,6 & 84,0 & 88,9 & 93,3 & 91,8 & 95,9 & 93,8 \\
\hline Noroeste e Norte & 26,5 & 34,9 & 49,5 & 55,3 & 69,8 & 79,9 & 86,3 & 87,4 \\
\hline Sul de Minas & 39,0 & 27,0 & 58,4 & 59,9 & 76,0 & 70,5 & 83,1 & 82,1 \\
\hline Triângulo & 73,0 & 75,0 & 89,6 & 91,0 & 93,5 & 93,3 & 96,6 & 95,0 \\
\hline Zona da Mata & 27,8 & 50,1 & 51,4 & 62,3 & 68,7 & 70,9 & 83,8 & 85,2
\end{tabular}

Fonte: Microdados da PIA/IBGE. Elaboração dos autores.

redução da competitividade potencial da atividade. $\mathrm{O}$ indicador do VTI/UL, apesar de estar acima de média do Estado, tanto em 1996 como em 2006, mostrou, no último ano, que houve diminuição da diferença em relação às outras regiões. $\mathrm{O}$ indicador $\mathrm{PO} / \mathrm{UL}$ ficou abaixo da média do restante do Estado em 2006, sinalizando uma queda no tamanho médio das ULs da região, superior às demais regiões. Em termos relativos, a produtividade do trabalho permanece igual, ficando em torno de $40 \%$ acima da média estadual da atividade.

$\mathrm{Na}$ outra região especializada do Estado, Jequitinhonha, Mucuri e Rio Doce, as variáveis medidas em valores mo- netários estão concentradas na atividade de "Metálicos", com percentuais próximos a $70 \%$. O pessoal ocupado também se encontra concentrado nessa atividade, mas em menor proporção $(57,0 \% \mathrm{em}$ 2006 e 44,2\% em 2006), indicando que essa atividade apresenta produtividade muito acima da média das demais atividades da região. $\mathrm{O}$ tamanho médio das ULs da atividade de "Metálicos", medido em termos de pessoal ocupado (PO/ UL), em 1996, atingiu 1.357, o maior resultado para o Estado, reduzindo-se, em 2006, para 432, ainda muito acima dos demais valores observados para todas as regiões. Comparando-se com a média do Estado para esse setor, esse indicador 
mostrava que essas unidades, em 1996, eram 7,2 vezes maior que a média estadual e, em 2006, ainda 3 vezes maior.

O ICUR da região para essa atividade diminuiu 23\% em 2006. Esse aumento da competitividade potencial do setor é decorrente de um aumento da produtividade do fator trabalho (crescimento de $18 \%$ ) em relação ao custo do fator (queda de 5,9\%), resultado corroborado pela redução expressiva no indicador PO/UL, destacada anteriormente.

$\mathrm{O}$ inverso acontece com a atividade "Alimentos, bebidas e fumo". Ela representa o maior percentual de ULs na região, está em segundo lugar no ranking regional do $\mathrm{PO}$, mas tem pouca importância no VTI. O ICUR dessa atividade aumentou significativamente em 2006. Essa queda de competitividade é decorrente de um aumento na remuneração média e uma redução na produtividade do trabalho.

\section{3_ As demais regióes do Estado}

\subsection{1_Alto Paranaíba}

O peso do Alto Paranaíba no VTI industrial do Estado é reduzido, isto é, cerca de $2 \%$ nos períodos inicial e final da série estudada. Em 2006, nessa região, a participação das quatro principais ativida- des no V'TI é de 94\%. Entretanto, o resultado se deve, principalmente, às duas maiores atividades - "Metálicos" e "Alimentos, bebidas e fumo", que, por si sós, concentram 83\% do VTI da região.

No período estudado, destacase a evolução da atividade "Metálicos", quando medida em termos das variáveis em valores, já que, em termos de pessoal ocupado e número de unidades produtivas, não há mudança significativa. Segundo o indicador VTI/UL, em 1996, o tamanho médio dessa atividade era 8,6 vezes maior que a média regional e 5,2 vezes maior que a média estadual. Em 2006, tornou-se 10 vezes maior que a média regional e 8,3 vezes maior que a média estadual.

O ICUR da região, para as duas principais atividades, reflete essa situação. Houve aumento relativo da competitividade nas atividades de "Metálicos" e "Alimentos, bebidas e fumo". Destaca-se aqui que, quando desagregado o índice, se nota que o crescimento da competitividade da atividade "Alimentos, bebidas e fumo" deveu-se mais a uma redução relativa da remuneração média da atividade, isto é, a taxas superiores a do Estado do que a um aumento relativo de produtividade. 


\subsubsection{Noroeste / Norte de Minas}

Essa região, assim como a anterior, representa uma parcela reduzida do VTI industrial mineiro: 3,7\% em 1996 e 2,4\% em 2006. O peso local das duas principais atividades saltou de 49,5\% em 1996 para 55,3\% em 2006. Desagregando-se essa análise, observa-se que a atividade de "Metálicos", a segunda em importância em 1996, foi superada, em 2006, pela atividade de "Têxtil, vestuário, couro e calçados", que aumentou sua participação de 20,3\% para 24,6\%. Outra atividade que tem sua posição relativa no VTI industrial reduzida em 2006 é a de "Alimentos, bebidas e fumo", passando de 16,4\% em 1996 para 7,5\% em 2006.

Houve um acréscimo no ICUR de todas as atividades na região, exceto para "Alimentos, bebidas e fumo", em que ocorreu uma redução relativa tanto na produtividade do trabalho quanto no custo desse fator, sendo a última mais significativa, ou seja, um aumento espúrio de competitividade. Dessa forma, a região tornou-se menos competitiva em todas as atividades analisadas, com a variação dos custos relativos da remuneração do trabalho sendo superior aos ganhos decorrentes da produtividade.

\subsection{3_Zona da Mata}

Nessa região também ocorreu, em 2006 , aumento da concentração do VTI indus- trial nas principais atividades. Das quatro principais, duas - "Alimentos, bebidas e fumo" e "Têxtil, vestuário, couro e calçados" - reduziram sua participação. A atividade "Madeira, celulose, edição e móveis" manteve-se praticamente constante, e a "Metálicos" aumentou sua importância relativa. Além disso, a atividade "Máquinas, equipamentos e veículos" aumentou sua participação de 5,3\% para 6,7\%. Portanto, pode-se concluir que essa região apresentou a maior mudança na estrutura produtiva, considerando-se o período analisado, com destaque para as atividades do complexo metal-mecânico, que engloba "Metálicos" e "Máquinas, equipamentos e veículos".

Entretanto, em termos de participação no emprego, essas atividades relacionadas ao complexo metal-mecânico não tiveram variação significativa: a participação de cerca de 16,0\% em 1996 teve ligeira redução em 2006 (14,4\%). A participação no total de unidades produtivas apresentou queda de 11\% em 1996 para 9\% em 2006.

Por outro lado, considerando-se o indicador de tamanho V'TI/UL, nota-se que a atividade "Metálicos" apresentou expressivo crescimento em relação à média do indicador para a região. Em 1996, o VTI/UL da atividade na região era 5,5 
vezes maior que a média e, em 2006, tornou-se 14,6 vezes maior.

A atividade "Máquinas, equipamentos e veículos" apresentou melhoria nos indicadores tanto em relação à média da região quanto em relação à média do Estado. Mesmo assim, tanto o VTI/PO quando o VTI/UL são inferiores às médias regionais e estaduais da atividade.

Considerando o período inicial, o ICUR para a Zona da Mata foi melhor em 2006 para as atividades "Extrativa", "Metálicos", e "Máquinas, equipamentos e veículos". No entanto, apenas as duas primeiras continuaram a apresentar índice menor que a unidade. Essas contribuíram para a melhoria na competitividade potencial da região, em sua maior parte atribuída a uma melhoria da produtividade do trabalho em relação à média estadual na atividade.

\subsection{4_Sul de Minas}

Nessa região, observou-se ligeira redução do peso econômico das quatro principais atividades no total regional, de cerca de 83,0\% em 1996 para 82,1\% em 2006. Embora o peso da região no emprego estadual tenha aumentado de $14,8 \% \mathrm{pa}-$ ra $18,9 \%$, sua participação no VTI se reduziu de $11,7 \%$ para $9,9 \%$.

Em 1996, a principal atividade em termos de VTI industrial era a de "Ali- mentos, bebidas e fumo", que respondia por 39,0\% dessa variável na região (26,9\% em 2006). No final do período considerado, foi superada pela atividade de "Máquinas, equipamentos e veículos", que passou a responder pela maior parte do VTI regional (33,0\% em 2006).

Chama a atenção, na região, a forte presença, em termos de geração de emprego, da atividade de "Têxtil, vestuário, couro e calçados", que respondia, em 1996, por 16,5\% do emprego e $19,5 \%$ das unidades produtivas, aumentando sua participação, em 2006, para $22,5 \%$ e $29,8 \%$, respectivamente. O tamanho médio dessas unidades (PO/UL) se reduziu no período, passando de 82,6 no ano inicial para 71,6 no fim da série estudada.

Cabe ainda destacar o crescimento da participação econômica da atividade de "Petróleo, álcool, farmacêutica e química", que saltou de 7,1\% para $11,6 \%$ do VTI regional, com pequeno aumento na participação na geração de emprego (de $9 \%$ para 10,3\%).

Apesar de o desempenho da região parecer favorável, houve crescimento relativo de competitividade potencial em apenas dois setores: "Têxtil, vestuário, couro e calçados" e "Não metálicos", com destaque para o crescimento, 
no primeiro setor, da produtividade do trabalho em relação ao Estado.

\subsubsection{Centro-Oeste de Minas}

Nessa região, observou-se o maior crescimento no número de ULs pertencentes ao estrato certo da PIA: $88,7 \%$ contra 40\% da média estadual. O mesmo se pode dizer em relação ao crescimento no emprego, de $97,5 \%$ contra $40,7 \%$ da média estadual. Com isso, a participação regional no número de unidades produtivas e no emprego aumentou, respectivamente, de 10,8\% e 6,9\% em 1996 , para $14,5 \%$ e $9,6 \%$ em 2006. A participação no VTI industrial mineiro, no entanto, reduziu-se de 3,8\% para 3,2\%. As quatro principais atividades regionais representavam, em 2006, 69,2\% do VTI, marca inferior ao verificado no início da série $(86,4 \%)$.

Enquanto a atividade "Metálicos" aumentou sua participação no VTI regional de $21,2 \%$ para $30,1 \%$, o caminho inverso foi percorrido pela atividade "Alimentos, bebidas e fumo", que teve sua participação reduzida de 38,0\% para 17,6\%. Essa atividade reduziu sua presença na economia regional em todas as variáveis selecionadas, ao passo que a primeira destacou-se na participação no VTI. Em ambas as atividades houve per- da, de acordo com o ICUR, de competitividade, e, nas duas, houve aumento da remuneração do fator trabalho e decrescimento na produtividade. Entretanto, a atividade "Metálicos" apresentou aumento mais significativo na remuneração do trabalho, como também redução menos significativa na produtividade.

Destaca-se ainda na região o aumento da participação relativa das atividades de "Petróleo, álcool, farmacêutica e química" (6,3\% em 1996) e "Não metálicos" (3,3\% em 1996), ambas atingindo cerca de $12 \%$ do VTI regional em 2006. Considerando a atividade "Não metálicos" com pequena participação no emprego regional (3,9\% em 1996 e 4,4\% em 2006), nota-se que a produtividade (VTI/PO) em relação à média regional cresceu consideravelmente, passando de um valor abaixo da média regional no início da série para 2,8 vezes maior à média em 2006. O ICUR também aponta nessa direção: a atividade apresentou a maior redução no índice, indicando maior aumento relativo no grau de competitividade.

Os resultados indicam mudanças estruturais significativas na região, com alterações relativas importantes na posição das principais atividades desenvolvidas. 


\section{7_Conclusão}

Neste artigo, buscou-se apresentar novas evidências sobre a competitividade da indústria mineira, considerando-se as suas regiões. Utilizando dados da PIA, no período de 1996 e 2006, tornou-se possível um estudo que lança mão de indicadores de produção, além dos indicadores de emprego tradicionalmente usados em estudos anteriores. A evolução positiva - e acima da média do País - da economia mineira pode ser resumida pela análise do indicador de competitividade. Em 2006, todas as oito atividades analisadas em Minas Gerais mostraram-se mais competitivas que a média nacional. O destaque positivo foi a atividade "Metálicos", que passou a apresentar produtividade duas vezes maior que a média setorial do País.

No panorama regional, os seguintes pontos se destacam:

i. A região "Central" destaca-se por ser a principal geradora do VTI: $55,9 \%$ do total do Estado, em 2006, e por apresentar redução na participação do emprego e dos salários. Por outro lado, essa redução foi acompanhada por um aumento da competitividade. Quatro atividades se destacaram:
"Extrativa", "Petróleo, álcool, farmacêutica e química", "Alimentos, bebidas e fumo" e "Máquinas, equipamentos e veículos". ii. As duas regiões especializadas do Estado, a região do Triângulo e a região do Jequitinhonha, Mucuri e Rio Doce, aumentaram ainda mais, em 2006, a concentração do VTI em sua principal atividade.

iii. A atividade principal do Triângulo - "Alimentos, bebidas e fumo" - apresentou redução na competitividade potencial relativa; a atividade "Metálicos", na região do Jequitinhonha, Mucuri, Rio Doce, mostrou ganho de competitividade. A utilização do ICUR aumentou a qualidade da análise sobre as transformações que as duas áreas sofreram, o que poderia ficar obscuro com o uso apenas das informações sobre o emprego setorial em cada região.

iv. Nas demais regiões do Estado, houve algumas alterações significativas na estrutura das atividades, tanto em relação ao emprego quanto à geração do VTI e, consequentemente, sobre a pro- 
dutividade, sugerindo que estudos posteriores investiguem mais aprofundadamente essas questões. Uma direção imediata é a desagregação dos setores nas regiões, que pode ser feita utilizando a classificação de divisão (2 dígitos da CNAE), ainda que se apresentem algumas restrições por conta do sigilo estatístico.

v. A região do Alto Paranaíba, apesar de ter peso pequeno no VTI estadual, apresentou crescimento no potencial competitivo nas duas principais atividades: "Metálicos" e "Alimentos, bebidas e fumo".

vi. Já a região Noroeste/Norte de Minas, também com percentual reduzido de participação no VTI regional, apresentou acréscimo no ICUR (perda de competitividade) de todas as atividades analisadas, exceto para a de "Alimentos, bebidas e fumo".

vii. A região da Zona da Mata apresentou aumento da concentração do VTI nas quatro principais atividades. O ICUR dessa região tornou-se melhor em 2006 nas atividades "Extrativa", "Metáli- cos" e "Máquinas, equipamentos e veículos".

viii. No Sul de Minas, a atividade "Alimentos, bebidas e fumo" foi superada em 2006 pela atividade "Máquinas, equipamentos e veículos", em termos de participação no VTI. Por outro lado, apenas duas atividades apresentaram crescimento relativo da competitividade potencial: "Têxtil, vestuário, couro e calçados" e "Não metálicos".

ix. No Centro-Oeste mineiro, destaca-se a atividade "Metálicos". Apesar do aumento na participação no VTI regional, a atividade apresentou redução no grau de competitividade potencial. Por outro lado, a atividade "Alimentos, bebidas e fumo", que possuía a maior parcela do VTI da região em 1996, apresentou perda de posição relativa em 2006 e também aumento significativo no ICUR (perda de competitividade potencial).

Os resultados apresentados, em decorrência do uso de indicadores mais completos do que apenas a informação sobre o emprego setorial e regional, en- 
riquecem a análise da estrutura industrial estadual. Ainda assim, cabe ressaltar que o indicador de competitividade aqui utilizado possui limitações. Para estudos futuros, além de investigar a competitividade por meio de outros indicadores, como, por exemplo, a produtividade total dos fatores, torna-se necessária uma análise da série como um todo.

Conforme destacado por Gonçalves et al. (2003), setores podem estar apresentando quebras estruturais em anos diferenciados, e essa questão, considerada regionalmente, ainda precisa ser investigada. É possível ainda com a mesma base de dados, detalhar as atividades em cada região, o que, mesmo com a limitação relacionada ao sigilo estatístico, permitirá análises mais completas da estrutura industrial das regiões mineiras. 


\section{Referências Bibliográficas}

BONELLI, Regis. Labor productivity in Brazil during the 1990s. Rio de Janeiro: IPEA, 2002. (Texto para Discussão, 906).

BRITTO, Jorge;

ALBUQUERQUE, Eduardo da Motta. Estrutura e dinamismo de clusters na economia brasileira: uma análise exploratória a partir dos dados da RAIS. In: TIRONI, Luiz Fernando. Industrialização descentralizada: sistemas industriais locais. Brasília: IPEA, 2001.

Cap. 1, p. 17-51.

CARVALHO JÚNIOR, Nelson

Simão de; RUIZ, Ricardo

Machado. Determinantes do desempenho das firmas a partir das novas capacitações internas: um estudo de firmas brasileiras. Revista de Economia Contemporânea, Rio de Janeiro, v. 12, n. 1, p. 97-127, jan./ abr. 2008 .

CROCCO, Marco Aurélio et al. $\mathrm{O}$ arranjo produtivo moveleiro de Ubá (MG). In: TIRONI, Luiz Fernando. Industrialização descentralizada: sistemas industriais locais. Brasília: IPEA, 2001.

Cap. 6, p. 179-235.
FEIJÓ, C. A.; CARVALHO,

P. G. M.; RODRIGUES, M.

S. Concentração industrial e produtividade do trabalho na indústria de transformação nos anos 90: evidências empíricas.

Economia, v. 4, n. 1,

p. 19-52, jan./jun. 2003.

FIGUEIREDO, Ana Tereza Lanna; DINIZ, Clélio Campolina. Distribuição regional da indústria mineira. Nova Economia, Belo Horizonte, v. 10, n. 2, p. 39-69, dez. 2000.

GONÇALVES, Eduardo et al. Competitividade industrial de Minas Gerais no período 19852000: um enfoque econométrico. Nova Economia, Belo Horizonte, v. 13, n. 2, p. 81-108, jul./dez. 2003. Disponível em: <http://www.face. ufmg.br/novaeconomia $>$.

Acesso em: 1 dez. 2008.

INSTITUTO BRASILEIRO DE GEOGRAFIA E ESTATÍSTICA - IBGE. Pesquisa Industrial Anual (PIA): 1996. Rio de Janeiro: IBGE, 1998, v. 15.

INSTITUTO BRASILEIRO DE GEOGRAFIA E ESTATÍSTICA - IBGE. Classificação Nacional de Atividades Econômicas (CNAE): versão 1.0. 2. ed. Rio de Janeiro: IBGE, 2004.
INSTITUTO BRASILEIRO DE GEOGRAFIA E ESTATÍSTICA

- IBGE. Pesquisa Industrial Anual (PIA): 2006. Rio de Janeiro: IBGE, 2008, v. 25

IPEADATA. Tabela Produto Interno Bruto (PIB) - indústria de transformação: valor adicionado a preços básicos (\% do PIB). Disponível em: < http://www. ipeadata.gov.br>. Acesso em: 10 dez. 2008.

MINAS GERAIS. Banco de Desenvolvimento de Minas Gerais. Minas Gerais do século XXI. Belo Horizonte, 2002. 10 v. Integrando a indústria para o futuro, v. 6 .

MOREIRA, Maurício Mesquita. A indústria brasileira nos anos 90. O que já se pode dizer? In: GIAMBIAGI, Fabio; MOREIRA,

Maurício Mesquita (Orgs.). A economia brasileira nos anos 90. Rio de Janeiro: Banco Nacional de Desenvolvimento Econômico e Social, 1999. p. 293-332.

NETTO, Cintia R. S.; CURADO, Marcelo Luiz. Produtividade do trabalho, salários reais e desemprego na indústria de transformação do Brasil na década de 1990: teoria e evidência. Revista de Economia Contemporânea, Rio de Janeiro, v. 9, n. 9, p. 485-508, set./ dez. 2005.
SIDRA. Tabela 2295 - Produção física industrial por tipo de índice e seções e atividades. Disponível em: <http://www.sidra.ibge.gov.br/>. Acesso em: 10 dez. 2008.

TOYOSHIMA, Silvia Harume; SILVA, Marcelo Pereira da. Competitividade e produtividade: uma análise comparativa do desempenho industrial de Minas Gerais, 1985-1996. Nova Economia, Belo Horizonte, v. 10, n. 1, p. $79-107$, jul. 2000.

Os dados utilizados fazem parte do Convennio de Cooperação Técnica celebrado entre o Instituto Brasileiro de Geografia e Estatística (IBGE) e a Federação das Indústrias do Estado de Minas Gerais (Fiemg). As opiniões aqui expressas são exclusivamente dos autores e não representam a posição das instituições.

E-mail de contato dos autores: antonio-braz.silva@ibge.gov.br juliana.alves@ibge.gov.br

\section{Artigo recehido em janeiro de 2009;} aprovado em janeiro de 2010. 
Anexo

Tabela 1_Compatibilização da classificação de oito atividades com as divisões (2 dígitos) da CNAE

\begin{tabular}{|c|c|c|}
\hline Atividades & $\begin{array}{c}\text { Código } \\
\text { CNAE }\end{array}$ & Descrição CNAE \\
\hline \multirow{2}{*}{ Alimentos, bebidas e fumo } & 15 & Fabricação de produtos alimentícios e bebidas \\
\hline & 16 & Fabricação de produtos do fumo \\
\hline \multirow{4}{*}{ Extrativa } & 10 & Extração de carvão mineral \\
\hline & 11 & Extração de petróleo e serviços \\
\hline & 13 & Extração de minerais metálicos \\
\hline & 14 & Extração de minerais não metálicos \\
\hline \multirow{5}{*}{$\begin{array}{l}\text { Madeira, celulose, edição } \\
\text { de móveis }\end{array}$} & 20 & Fabricação de produtos de madeira \\
\hline & 21 & Fabricação de celulose, papel e produtos de papel \\
\hline & 22 & Edição, impressão e reprodução de gravações \\
\hline & 36 & Fabricação de móveis e indústrias diversas \\
\hline & 37 & Reciclagem \\
\hline \multirow{7}{*}{$\begin{array}{l}\text { Máquinas, equipamentos } \\
\text { e veículos }\end{array}$} & 29 & Fabricação de máquinas e equipamentos \\
\hline & 30 & Fabricação de máquinas para escritório e equipamentos de informática \\
\hline & 31 & Fabricação de máquinas, aparelhos e material elétrico \\
\hline & 32 & $\begin{array}{l}\text { Fabricação de material eletrônico e de aparelhos e equipamentos } \\
\text { de comunicação }\end{array}$ \\
\hline & 33 & $\begin{array}{l}\text { Fabricação de equipamentos de instrumentação médico-hospitalares, } \\
\text { instrumentos de precisão e ópticos, equipamentos para automação industrial, } \\
\text { cronômetros e relógios }\end{array}$ \\
\hline & 34 & Fabricação e montagem de veículos automotores, reboques e carrocerias \\
\hline & 35 & Fabricação de outros equipamentos de transporte \\
\hline \multirow{2}{*}{ Metálicos } & 27 & Metalurgia básica \\
\hline & 28 & Fabricação de produtos de metal - exceto máquinas e equipamentos \\
\hline Não metálicos & 26 & Fabricação de produtos de minerais não metálicos \\
\hline \multirow{3}{*}{$\begin{array}{l}\text { Petróleo, álcool, farmacêutica } \\
\text { e química }\end{array}$} & 23 & $\begin{array}{l}\text { Fabricação de coque, refino de petróleo, elaboração de combustíveis nucleares e } \\
\text { produção de álcool }\end{array}$ \\
\hline & 24 & Fabricação de produtos químicos \\
\hline & 25 & Fabricação de artigos de borracha e plástico \\
\hline \multirow{3}{*}{ Têxtil, vestuário, couro e calçados } & 17 & Fabricação de produtos têxteis \\
\hline & 18 & Confecção de artigos do vestuário e acessórios \\
\hline & 19 & $\begin{array}{l}\text { Preparação de couros e fabricação de artefatos de couro, artigos de viagem } \\
\text { e calçados }\end{array}$ \\
\hline
\end{tabular}

